\title{
The seismic future of cities
}

\author{
Roger Bilham
}

Received: 10 July 2009 / Accepted: 17 July 2009 / Published online: 2 September 2009

(C) The Author(s) 2009. This article is published with open access at Springerlink.com

\begin{abstract}
The final projected doubling in Earth's population in the next half century, requires an additional 1 billion housing units, more dwellings constructed in a single generation than at any time in Earth's history. Earth's tenfold increase in population has occurred during a time that is short compared to the return time of damaging earthquakes. In the next century, therefore, earthquakes that had little impact on villages and towns, will be shaking urban agglomerations housing upwards of 12 million people. An epicentral hit on a megacity has the potential to cause 1 million fatalities. The incorporation of earthquake resistant structures in the current global building boom, despite successes in the developed nations, has been neglected in the developing nations where historically earthquake damage has been high. The reasons for this neglect are attributed to indifference, ignorance and corrupt practices, not due to an absence of engineering competence. Never has a generation of earthquake engineers been faced with such a grave responsibility to exercise their skills, both political and technical, as now.
\end{abstract}

Keywords Earthquakes · Megacities · Earthquake-fatalities · Corruption

The eye is bewildered by "a city become an heap". Robert Mallet (1862).

\section{Introduction}

Homo Sapiens is unique on our planet in its need to construct dwellings, to aggregate those dwellings in cities, and to construct both, largely oblivious of their vulnerability to earthquake damage, or for that matter any other kind of infrequent catastrophe. It is easy to protest that, no, we have learned how to construct buildings that do not collapse, and that we know where to construct to minimize the impact of earthquakes, but recent history shows that earthquake resistance is a local exception rather than a global rule. A slow steady increase in deaths and

\footnotetext{
R. Bilham (凶)

CIRES and Department of Geological Sciences, University of Colorado,

Boulder, CO 80309-0399, USA

e-mail: rogerbilham@gmail.com
} 
economic losses from earthquakes is interspersed with remarkable catastrophes that remind us of how far the gap between knowledge and its application has widened in those countries most disadvantaged by earthquakes.

It is the historical record that provides us a clue as to what lies in our future, and I propose to devote most of this article to an examination of this aspect of the human predicament. From our past we can glimpse the perils to an increasingly urban society indifferent to a guaranteed seismic future. Though it is accidental that the notion of an urban earthquake is built into the word seismicity- "seismic-city"-it is no accident that the only earthquakes that are of real concern to society are those that destroy buildings. The more buildings that are damaged the more certain is the earthquake to be remembered, and the more likely is the reconstruction of that city to incorporate a measure of resilience to the next earthquake. The notion of urban earthquakes - those that shake a city with damaging accelerations - say those exceeding Intensity VII on the Modified Mercalli scale, has thus been around since earthquakes were first described in biblical times. Historical earthquakes are remembered for the ruins they caused.

Nine thousand years ago humankind formed the world's first cities, colonies of dwellings, each family dwelling surrounded by four walls and a roof. The dwelling units of these early cities were formed from the materials available to hand: straw, twigs, and mud. The earliest Neolithic cities that we know of Mellaart (1967) were constructed of mud, a material that can be moulded when wet, yet becomes brittle when dry. For these early city dwellers mud provided two additional benefits-low thermal conductivity and high thermal capacity - thereby providing rudimentary air conditioning — cool in summer, warm in winter. Mud can be painted, swept and easily repaired. Mud houses do not burn. But most of all, mud is dirt cheap, and to this day mud is the construction method of choice in low income families throughout the developing world. But mud is a killer-mud houses collapse in earthquakes.

In November 2008 as I write this article the survivors of a 100 villages in Baluchistan wee clearing up the ruined fragments of their homes as they prepared for a winter of sub zero temperatures in tents. More than 300 villagers were killed in mud-adobe structures, whereas many of their neighbors in reinforced concrete structures survived. One of the questions that I pose in this article concerns why the knowledge of 9,000 years of city collapse in earthquakes, and a known cumulative death toll of more than 10 million people, has not led to safer construction everywhere.

Robert Mallet and John Milne were among the first to quantify how and why buildings were damaged by earthquakes. On 13 October 1900 John Milne wrote in the flyleaf of a copy of his 1892 book on earthquakes presented to a friend "If you compare the contents of this volume with its reproduction, and a companion volume called "Seismology" issued in 1898 you will realize the rate at which a neglected study is advancing." Milne (1891) noted that in many societies (Japan) solutions to resisting earthquake damage were incorporated into local construction practices, whereas in other societies (Italy) architects were largely oblivious to the need to design for future shaking. He was obviously speaking of recent disasters and can be forgiven for generalizations and exceptions. Thus the late fifteenth century earthquake resistant house described by the Italian architect Pirro Ligorio (Guidoboni and Ebel 2009) was theory rather than widespread practice. Milne shows graphic depictions of failed structures throughout the world, including two from the 1868 Hayward fault earthquake. In the late nineteenth century architects in San Francisco, learning from these failures, were successfully implementing design features that would make their new constructions earthquake resistant (Tobriner 2006). Milne (1912) who in his catalogue of historical earthquakes estimated that more than 12 million people had been killed by earthquakes in the preceding 2,000 years, would have appreciated the sophistication of earthquake engineering that 
occurred in the century following his words. He would have also been astonished that within that same century, even with these advances, earthquakes would claim a further 2 million lives.

\section{Road map to the article}

I provide the following overview of the order in which materials are presented. I first review global population growth and its distribution, followed by a summary of the historical earthquake record. An extended following section describes archival problems in seeking the true location, fatality-count and extent of damage of former earthquakes. This is followed by sections describing the spatial distributions of destructive earthquakes, and by simple statistical analyses of trends in the fatality rate. This is followed by a section focused on the Alpine/Himalayan/Indonesian collision zone where $85 \%$ of all earthquake fatalities have occurred. Tectonic strain rates in this region (the southern edge of the Eurasian plate) are slow and distributed over a wide area. The assessment of seismic risk in some of these areas (India) is hampered both by a short historical record, and by difficulties in identifying causal faults in a flexural stress regime. I mention briefly newly developed tools that have had reasonable success at estimating the death-toll from an earthquake within $30 \mathrm{~min}$ of its occurrence. The forecast of future fatality rates in urban settlement is the subject of the last third of the article. Numerous problems attend the forecast of future seismicity in several of the developing nations. I identify four problems that hinder our estimation of seismic risk in regions where the historical record may be short, and a dozen societal flaws that in certain countries thwart the best efforts of engineers to implement earthquake resistant construction. I conclude that in the past several decades we have lost an important opportunity to build safe structures in the world's rapidly growing urban settlements, mostly in the developing nations, and that as a result, a rising death toll from earthquakes in the next several decades is inevitable.

\section{Population demographics}

At the time of the first cities roughly 10,000 years ago world populations have been estimated as between 1 and 10 million (McEvedy and Jones 1978; Thomlinson 1975). The transition from Neolithic hunter-gathers to Bronze-age pastoral and farming communities led to a need for permanent structures, traces of which are increasingly evident starting roughly 5,000 years ago, an approximate date for the start of urbanization. It is clear, however, that city life, though made possible by an abundant supply of food supplied by the surrounding rural populations, was an unhealthy environment, with communicable diseases holding populations firmly in check. Thus populations grew erratically from 7,000 to $0 \mathrm{BC}$, interrupted by periodic epidemics in different continents that continued in the next 1,500years. These epidemics led to dramatic (30-90\%) but transient local reductions in population. Fewer than 400 years ago advances in medicine reduced the mortality rate, raising life expectancies from around 20 to more than 60 years. The extended life span caused by the increased availability of medicine, improved sanitation, and clean water, caused world populations to rise rapidly, starting in the eighteenth century (Fig. 1) and continuing at present.

World populations even now in the presence of mandatory census compilations are inaccurate, and estimates of early populations are doubly so, based as they are on numerous assumptions. The data used for Fig. 1 show high and low estimates (Durand 1974; Thomlinson 


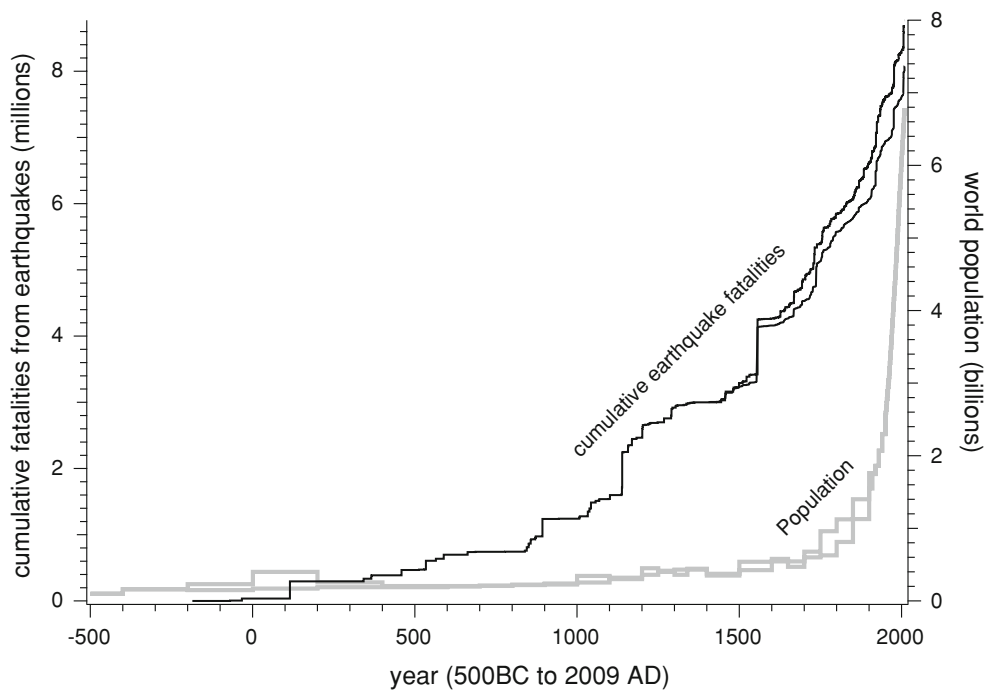

Fig. 1 Earthquake fatalities since $500 \mathrm{BC}$ compared to estimated global populations (it grey). High and low estimates for global population are from McEvedy and Jones (1978) and Thomlinson (1975). High fatality count edited from Dunbar et al. (1992). Low fatality counts since 1500 from Utsu (2002). Milne's (1912) compilation lists 6,000 entries with a cumulative death toll of around 12 million

1975; McEvedy and Jones 1978; Biraben 1980; Haub 1995; United Nations 1999; US Census Bureau 2008).

It is convenient to consider the doubling time for world populations to realize how unusual is our present predicament. The first doubling occurred between 500BC and around 1000AD when estimated populations increased from $\approx 120$ million to $\approx 250$ million. It took a further 650 years to double the population to 500 million. Populations had doubled again to $\approx 1,000$ million by 1800 , and redoubled in 1,920 to 2,000 million. A further doubling had occurred by 1975 , and populations are expected to slowly double again reaching a 2,020 population of 8,000 million. The successive time intervals between each of these population doubling times-1,500, 650, 150, 120, 55 and 70 years-have decreased from taking place over thousands of generations (pre-1600 life expectancies were less than 30 years), to occurring in a single generation.

Urban growth has absorbed most of the world's increased population. Cities not only host more families but act as a magnet drawing in rural populations who are unable to survive in rural communities. There is nothing new in rural to urban migration, but prior to 1800 the city acted as a black-hole killing off its inhabitants and keeping pace with both the flux of new births and influx of rural populations seeking life (but often finding death) in the cities. After the widespread application of medicine c. 1800 the city ceased to be a setting where life expectancy was short, and as a result urban populations began to rise (Fig. 4). In 2009 the world officially became an urban planet when city dwellers for the first time in history outnumbered rural dwellers.

Since 1950 the contribution to increasing global populations has occurred mostly in the cities of the developing world where it has doubled every 20 years or so, fueled by an annual population increase of $2-3 \%$ (Fig. 2). According to UN predictions, rural populations in the developing nations are close to an anticipated peak of about 3,200 million people, roughly ten times that in the Industrial Nations where rural populations continue to fall. The modest 


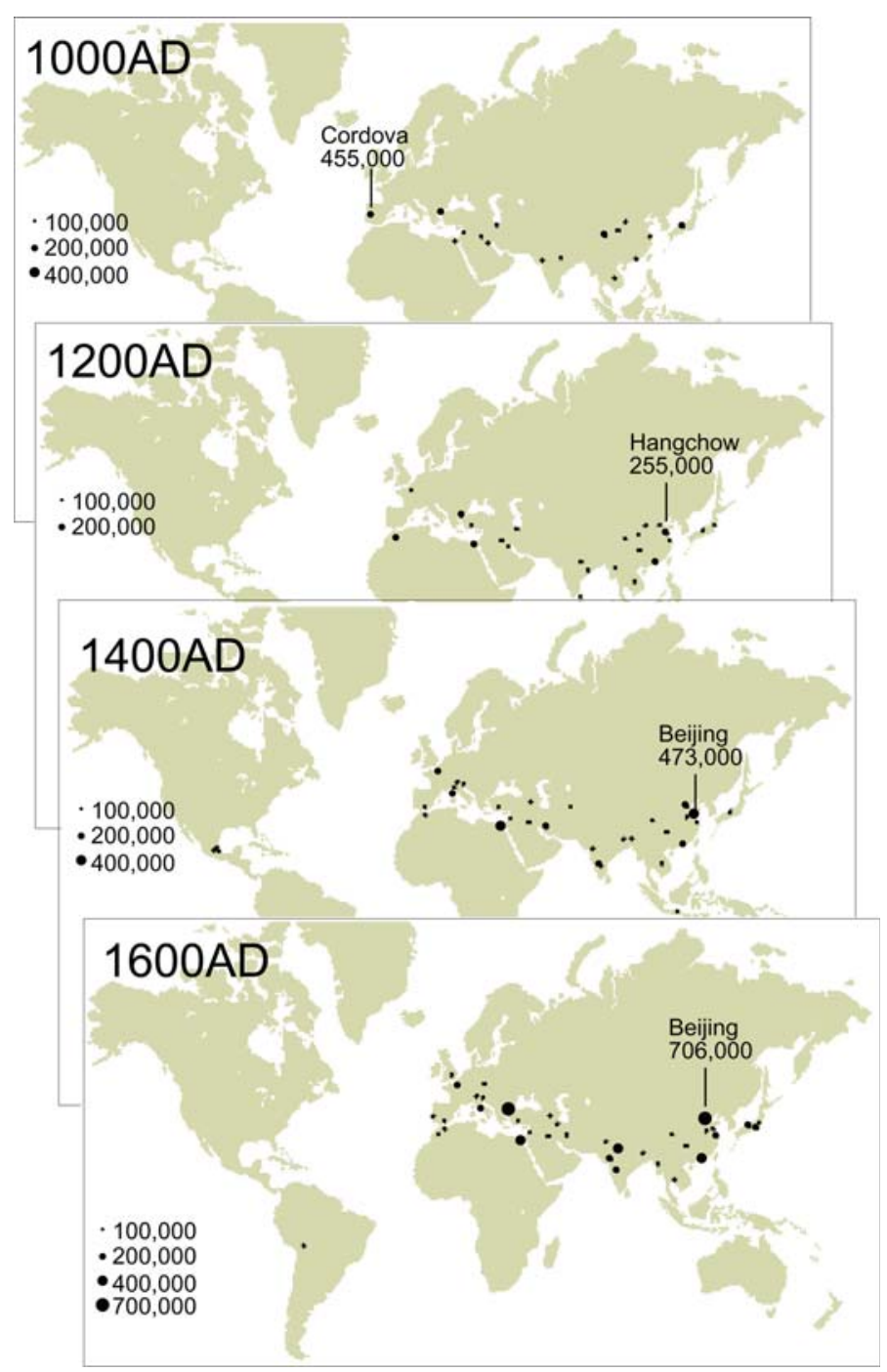

Fig. 2 The world's largest cities from 1000AD-1600AD, showing in each case the population of the world's largest city at 200 year intervals. Although Rome (AD 14 population 4.9 million) and Bagdad (AD 900 population 900,000) exceeded the size of all those depicted, not until 1800 did any other city attain a population of 1 million. [data adapted from Chandler and Fox (1974) and Chandler (1998)]

increase in urban population in the Industrial nations is expected to continue to rise, but by 2030 the total population in the Industrial nations is expected to peak and then decline (United Nations 2009). A corresponding peak in the total population of the Developing Nations is not expected for a further quarter century.

In the past 200 years populations on Earth have increased by an order of magnitude. One consequence of this tenfold increase is that whatever we conclude about past risks from historical earthquakes our findings must be adjusted to account for this remarkable demographic change. 


\section{Fatalities from earthquakes}

This article may be faulted for its morbid obsession with fatalities, rather than other aspects of earthquake damage-injuries and economic losses. The reason for this focus is that most fatalities are caused by the collapse of buildings. They thus provide a quantitative measure of structural failure, something that can be addressed by improved engineering. The secondary effects of earthquakes-landslides, rock-falls, tsunami-have occasionally dominated the fatality count, and are not directly the result of flawed engineering. Two of the largest disasters in the past 500 years fall into this category: the 1556 earthquake in China when many deaths were caused by ground instability and hillside collapse, and the 2004 Indian ocean tsunami with its selective death toll on and near beaches on a public holiday. One can argue in hindsight that many of these accidents could have been avoided had appropriate planning preceded these catastrophes. Few societies are willing to restrict the right of its citizens to construct in vulnerable settings. Fatality counts for early earthquakes are often inflated since they are frequently estimated by historians writing many years after the event, with relatively modest access to contemporary materials. These materials are preserved most accurately in societies with central administrations, who have maintained written records of repairs, taxes, and sometimes tax-relief, following the earthquake. For pre-nineteenth century earthquakes, the death-toll, location and the date of the earthquake are the only quantifiable parameters associated with the earthquake. A very readable summary of the attributes of a dozen early and recent earthquake catalogues of earthquakes can be found in the appendix of Ambraseys et al. (2002).

Mallet's original catalogue of $>5000$ earthquakes was compiled with help of his eldest son, and printed in successive editions of the British Association for the Advancement of Science over a period of 5 years starting in 1850. The first two sections of their report (Mallet $1851,1852,137$ pages in total) describe methodology, and the listings of earthquakes since biblical times record physical phenomena (Mallet 1853, 1854, 1855, 587 pages in total) but are sparse on fatality counts. Mallet's catalogue includes entries from the earlier catalogues of Hoff (1840) and Perrey (1844-1853), and includes numerous new materials, from ship's logs and from the writings of travelers and historians ending in 1842, at which point Mallet points the reader to Perrey's annual catalogues from 1842 onward. These have been subsequently incorporated into later listings. The catalogue compiled by Thomas Oldham and his son Richard, for earthquakes in India, for example, extracts materials of relevance to India, and adds others (Oldham 1883). Milne's (1912) 80-page somewhat telegraphic catalogue repeats data from these earlier compilations, omitting small earthquakes from Mallet's catalogue but adding additional events compiled from an enquiry to officials in all parts of the British Empire. These and later catalogues for various parts of the world have now been superseded by studies in which great care has been devoted to avoiding the repetition of error (Ambraseys et al. 2002; Stucchi et al. 2008). The success of these recent studies depends on the thoroughness with which each earthquake is linked to source materials that can be verified. For many earthquakes this requires the reproduction of primary accounts and a commentary on their interpretation.

However, despite these careful studies numerous recent catalogues have perpetuated errors, and reinserted items that were removed from previous catalogues. The readily available NOAA catalogue first published by Ganse and Nelson (1982) and updated by Dunbar et al. (1992) compiles data from numerous sources and subsequent catalogues and incorporates data available in accounts of earthquakes written by some primary and numerous secondary authors, who in turn cite previous summaries. As a result, the compilation contains duplicate entries and conflicting information for many events, and must be used with caution. 
Despite its shortcomings on the critical evaluation of what to believe and what to ignore, the published NOAA catalogue provides a listing of source materials from which the reliability of the data can sometimes be evaluated. An online version of this catalogue has now been reduced in length by the critical assessment and removal of numerous dubious accounts, but unevenly incorporates materials and case histories of earthquakes published in the past several decades: http://www.ngdc.noaa.gov/nndc/struts/form?t=101650 \&s=1\\&d=1. A carefully evaluated listing of historical earthquakes has also been published by Utsu (2002) and this too is available digitally, updated to the present with $>10,000$ entries http://iisee.kenken. go.jp/utsu/index_eng.html. This on-line catalogue includes many duplicate reports of events with "flags" alerting the unwary to the possibility that some entries may be based on unsound reporting. The most recent catalogue of these post-1900 earthquakes-Pager-Cat (Allen et al. 2009) is based on eight earlier catalogues http://earthquake.usgs.gov/research/data/ pager/ and makes no attempt to evaluate original accounts. Instead, Allen et al. (2009) define rules for the quantification of fatality counts from poorly specified raw data, to provide a measure of uncertainty to the data.

\section{Why do catalogues of historical earthquakes abound in error?}

\section{It is not for one moment supposed that this Catalogue is free from omissions and mistakes. John Milne (1912).}

In Fig. 1 the cumulative death toll from earthquakes shows two curves that diverge after 1500. Other catalogues that could have been plotted would show an even greater divergence. The essential problem with catalogues of historical earthquakes is that unlike lists of triangulation observations in which systematic and random errors can be rigorously quantified, none of the parameters of historical entries come with an estimate of uncertainty. Mallet (1852) observes that often in different accounts of the same earthquake "the descrepancies are marvellous". Some earthquakes in early catalogues are pure fiction. Ambraseys et al. (2002) argue that more than 50\% of all historical earthquakes listed in pre-common-era catalogues are untrustworthy. I provide below some examples from the past 400 years illustrative of problem entries.

\subsection{Detection threshold and incompleteness}

The contribution to the total fatality count is systematically underestimated by the absence of information for the hundreds of earthquakes for which no numerical fatality count is given by historians, and for the even greater number unknown to historians. The question arises, as in earthquake magnitude, is there an earthquake whose death toll cannot escape global notice? The answer is, of course, that this detection-threshold has decreased through time. Although it is now essentially impossible for the worldwide news media to omit recording a single fatality in an earthquake, in the past it was quite common, especially in regions of low population density. Early earthquakes with low impacts on a literate society tend to be forgotten and their records lost.

\subsection{Chronologies: arithmetic and misunderstandings}

On each continent, and sometimes in different parts of that continent, early societies developed their own methods of reckoning time, all linked to astronomy, but all with differing starting points, and each regulated by different celestial clockwork (Duncan 1998). The links 
between these chronologies can be established by synchronizing eclipses, meteors and comets described in each (e.g. Gouin 1979) and scholars have become adept at translating dates into local times and GMT. Richard Oldham encountered this problem in ascertaining the times of arrival of waves from the 1897 in India where as late as 1906 local time was set by the sundial at midday throughout most of the country. Although, catalogue problems can occur due to arithmetical errors in date conversions, a more frequent problem in earthquake compilations occurs where seismologists, eager to record new earthquakes, have entered the same earthquake as two earthquakes oblivious the existence of these different chronologies. Ambraseys (1962) points at this grave error in a catalogue by Willis (1928) which duplicates many earthquakes by catalogueing the same event as occurring in AD (anno Domini) and also in the same numbered (unconverted) year in AH (anno Hegirae-in the year of the Hijra). In some instances Willis triplicated the earthquake as the result of a \pm 1 year arithmetic conversion error between the two calendars.

\subsection{Conflation: the earthquake occurred there, not here}

The evolution of place names since classical times (Anthon 1850; Cunningham 1871), and the existence of many cities with similar or identical names means that some earthquakes can be assigned two (or more) locations, only one of which is correct. Once this conflation has been initiated it requires a considerable effort to eradicate spurious location errors from a catalogue. An example is the 28 December 893 Daibul earthquake in Armenia (Dvin, $40.02^{\circ} \mathrm{N}, 44.58^{\circ} \mathrm{E}$ ), that appeared in Oldham's (1883) Indian catalogue as a result of a passage in one account mentioning "outer India" (Ambraseys and Jackson 2003). The ruin of Daibul in Armenia was identified incorrectly with the ruins of Debil (Daybul, Bhanbore) near Karachi in Sindh province, and although there is evidence that earthquakes may have shaken this part of the Indus delta, and Kufic inscriptions found there have been interpreted as indicating reconstruction (Ghafur 1966; Kovach et al. 2008), there is no evidence for earthquake damage to Banbhore in AD 893 (Khan 1964).

\subsection{Tangshan 1976: elusive numbers}

For very destructive earthquakes, even in recent time, it is possible that numbers may be uncertain. For example, the numerical death-toll for the $\mathrm{Mw}=7.6$ Tangshan earthquake of 27 July 1976 is listed in many catalogues somewhere between the official count of 242,419, the high initial estimate of 655,000 , and early, educated guesses, of visitors to the area of 750,000 . The elusive number was initially inflated by uncertainty in estimating the number of dead in families in which there were no survivors, and from a consideration of estimated head-count of the pre-earthquake population (Yong et al. 1988). In 7,218 households all the family members were killed by the earthquake. Most catalogues now list the official count pf 242,419. Marza (2004) questions the death-toll of the Izmit/Kocaeili earthquake of 1999 (also $\mathrm{Mw}=7.6$ suggesting that the true numbers may have exceeded twice the official count of 17,127 .

\subsection{Assam, 1943: a secret earthquake}

In rare cases fatality counts may be suppressed for political expediency, for example, as occurred in Assam 23 October 1943 in World War II. Earthquake damage from this $M \approx 7$ earthquake was withheld from letters home and local news reports in case it proved of strategic 
advantage to the opposing side. Doug Warr writes in 2002 "At the time I was with a medical unit stationed on the Manipur road, seven miles from Dimapur. I was awakened in the night by violent shaking - so violent that I found myself clinging desperately to the charpoy to avoid being shaken off. There was a rumbling noise. I don't know how long it lasted-perhaps a few minutes-and then it subsided to occasional slight tremors. In the morning we discovered that there were fissures and great unevenness in what had previously been level ground, trees had fallen and buildings had been damaged. There was some damage to the Manipur road, I think to the bridges on either side of my unit, but for security reasons a complete ban was imposed on the mention of any consequences of the quake so we never heard precise details. Of course, rumour was rife and we heard lurid accounts of fissures that had opened and swallowed men and vehicles but these were never substantiated and may have been figments of somebody's imagination. We shall never know" (letter to Martin and Szeliga 2009)

News of large fatality early earthquakes tend to be spoken about and recorded in more sources, and hence their survival is more likely, but the chances are thereby increased that numbers become subsequently inflated, sometimes to mythical proportions. My last examples are of what many now call fake-quakes — entries about disasters that are not earthquakes, but which have been recorded as such (Musson 2004; Belletatti et al. 2007).

\subsection{Beijing: a mythical earthquake}

An earthquake allegedly occurred near Beijing in 1662 and appears in many catalogues associated with 300,000 deaths. It is mentioned in a book by Ball (1904) introduced by the following remarks: "As a general rule earthquake shocks would not appear to be infrequent in China, and not of serious import." The following entries on his list are entered without attribution: AD1662 - one in China, when 300,000 persons were buried in Beijing alone, AD 1731-another, when 100,000 persons were swallowed up in Beijing. Drake (1912) reluctantly repeats the first of these earthquakes in his book, with an (almost) verbatim, but qualified entry-June 1662-Chihli-According to Ball an earthquake during this year was so violent at Peking that "300,000 people were killed at that place alone." I have not been able to verify this report. - but he adjusts the date of the second adding information from an unnamed source: 30 September 1730_Chihli-This earthquake was followed by after-shocks until October 8th. At a place 12 miles west of Peking the earth cracked open. In Peking and the surrounding country 100,000 people were killed. The 1662 and 1731 earthquakes listed by Lee et al. (1976) are relatively modest and their catalogue is devoid of fatalities. Ganse and Nelson (1982) reduce the fatalities in the June 1662 event to 600 but list 100,000 for the 1731 earthquake citing "US Congress: Great earthquakes, March 1888 Volume 1". This 1888 listing by Congress was extracted from the Baltimore Sun 1888 and does not mention the 1662 earthquake. Hirota (1908) mentions neither earthquake. Latter (1969) lists 300,000 deaths for 1662 citing Daly. Dunbar et al. (1992) list both of Ball's high numbers, but remove both events from the 2009 on-line NOAA searchable catalogue. Utsu's catalogue lists the 1662 earthquake as "mythical" and casts doubt on the year and number of deaths for the 1731 earthquake.

\subsection{Calcutta: a fake-quake}

A spurious event that is ubiquitous in most twentieth century elementary texts and numerous web pages listing the world's worst earthquakes is a 1737 storm surge and cyclone in Calcutta, that is alleged to have killed 300,000 people. Whether or not an earthquake, the numerical count is clearly bogus because the population of Calcutta in 1737 was less than 
30,000 , and the number of burials in the local church increased by a mere handful in 1737 , compared to previous and succeeding years. In this case the error can be traced to magazine accounts based on reports from captains of ships returning from Calcutta after the storm (Bilham 1994). In some of these accounts the number of deaths is listed as 3,000, a number that is consistent with the Fort William records of the East India Company as an estimate of the number drowned in the low lying areas of Calcutta. i.e. the number drowned was accidently exaggerated by two orders of magnitude when reported in magazines in Europe. The East India company ledger written in Fort William describing the damage to shipping and to the infrastructure of the port-a hand-written account-makes no mention of earthquake shaking. If there were, an earthquake during the storm it is likely to have been quite modest (e.g. $M<4.5$ ) to have not been worth mentioning by the East India Company. The event is missing in Mallet's catalogue and enters the world's catalogues following Oldham's (1883) entry. Milne (1912) adopts it and only recently have catalogues begun to omit it.

\subsection{Sindh: an unquantifiable earthquake}

In many cases an historical earthquake will occur whose primary source material conveys indisputable evidence for a damaging earthquake, but contains insufficient information to assign a magnitude, a date, a geographic location, or even certainty as to the name of the town involved. Despite this ignorance the earthquake can be found in present day catalogues assigned with one, or all, of these parameters. Once these materials have been provided by one author they tend to taken in good faith by the next investigator, each repetition adding layers to a false cloak of credibility. An example of this "invention" of quantified materials for a real earthquake is the 1668 Samawani earthquake in the Sindh province of Pakistan. The primary source of information for the Samawani earthquake comes from the Persian historian Musta'idd Khan who in the reign of the Emperor Aurangzeb notes that in May 1668 a report was received from the Mughal province of Thatta that an earthquake had damaged the town of Samawani. The account first appeared in earthquake catalogues in Oldham (1883) and reads as follows "At this time (between the 1st and 10th Zi hajja, 1078 AH) a report was received from the Soobah of Tattah that the town of Samawani (or Samanji) which belongs to the Parganah of Láhori had sunk into the ground with 30,000 houses, during an earthquake". Other translations are reproduced by Ambraseys (2004) and Bilham et al. (2007). In none of these translations is the day of the earthquake stated, and although it is bracketed by the dates of the preceding and following entries (2-11 May 1668), it may have occurred several days or weeks earlier as a result of the transit time of the information. In these several translations the name of the town is rendered as Samaji (Elliot 1857), Samanji and Samawani (Sarkar 1947; Bibliotheca Indica 1874). In 1596 Samawani was the fifth largest revenue-producing city in the administrative province of Nasarpur, surrounding the present day location of a town of that name $\left(25^{\circ} 31^{\prime} \mathrm{N}, 68^{\circ} 37^{\prime} \mathrm{E}\right)$. The precise position of ancient Samawani remains presently conjectural, but was apparently known to Hodīvālā (1939) as a village of 500 houses. Unfortunately Hodivala omitted its coordinates from his account, and since we have no definitive location and only one observation, the assignation of coordinates or a magnitude is conjectural, yet several authors have felt compelled to provide both, with magnitudes in the range $7<\mathrm{Mw}<7.6$, and coordinates accurate to $10 \mathrm{~km}$. Some authors have even seen fit to invent a tsunami as the cause for damage to Samawani (Murty and Rafiq (1991)). The fictitious location assigned to this damaging earthquake is the lower Indus Delta west of Karachi, whereas its probable location in ancient Nasarpur province places it NE of Hyderabad more than $100 \mathrm{~km}$ inland. As a result of its repetition in numerous catalogues the 
earthquake has taken on a life of its own and now appears in reputable catalogues, sometimes with several entries that appear to confirm the invented or simplified truths of earlier guesses. No fatalities are recorded to have occurred in this earthquake although the account has suggested to some, that many fatalities may have occurred. The event is not listed by Utsu (2002) but three qualified entries each with $\mathrm{Mw}=7.6$ appear in his 2009 on-line web-listing.

\section{Future findings of historical earthquakes?}

"In conclusion, I would repeat my conviction that a further expenditure of labour in earthquake catalogues of the character hitherto compiled..... .is now a waste of scientific time and labour"

Robert Mallet, British Association, Bath, 1888

Carefully researched reports of newly discovered information concerning the occurrence of earthquakes in Europe, China and Japan have now been published (Ambraseys and Melville 1982; Ambraseys 2009 and references therein; Guidoboni et al. 1994). We can anticipate that the historical record in many parts of the world will continue to improve from this archival research. The Vatican library, for example, remains a largely untapped resource for earthquake information that may eventually be examined by earthquake historians. However, in many parts of the world the survival of quantifiable accounts of earthquakes has been compromised by climatic and insect attack, fire and warfare. The loss of the Jesuit records from India in the 1755 Lisbon earthquake, was dealt a double blow when in 1774 the order requested the hand-written duplicates of the records maintained in Goa to be dispatched to Europe. The requested records were considered waste-paper by a belligerent captain who set fire to them (Correia-Alphonso 1969, citing Schurhammer 1962). Other records of the Indian Jesuits in southern India were burned by the Dutch. In the eighteenth century, the historical records of Sikkim written on wooden tablets were destroyed when they were used as roofing tiles by an invading Nepalese army.

Although regional catalogues based on the work of historians vigilant to first-hand accounts of earthquakes have now superseded earlier catalogues of uneven credibility, the suppression of incorrect information remains an ongoing task. One feature of new catalogues is to include bogus events with clear statements of the reasons for doubting their validity. Since an unqualified statement of error itself can be viewed later as an opinion subject to discussion, these faulty entries must be supported by a transparent and often tedious exposition of the reasons for the error. A satisfactory approach to this problem has been to lay out a hierarchy of citations demonstrating the dendritic growth of repetition and insertion from earlier source materials. This can be a lengthy and painstaking proposition requiring many pages devoted to identifying the source materials available to subsequent writers, and for this reason it has not been completed for many earthquakes. Stucchi et al. (2008) provide several case studies and Albini (2004) provides examples of the derivative nature of historical materials in the eastern Adriatic coast.

\section{Working with what we have}

An accurate listing of fatalities for earthquakes throughout the historical record is thus unavailable. An idea of the incompleteness of the historical record can be gained by a glance at Fig. 5, where the data available to the present are plotted as a function of time. All earthquakes for 


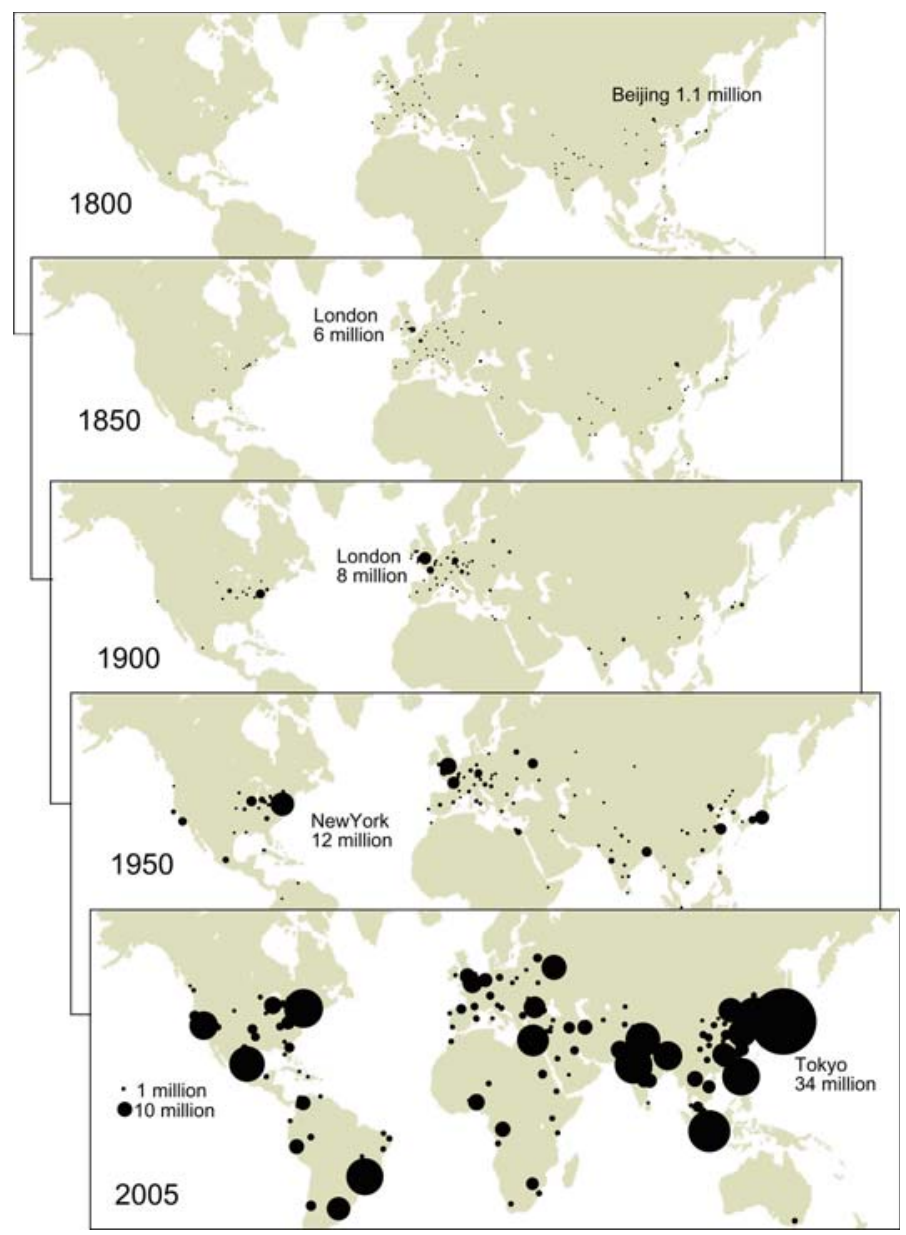

Fig. 3 City populations 1800-2000 with scale shown in the 2005 map. In 1800, and for the first time since ancient Rome, a city hosting more than a million people appeared. Urban populations have increased tenfold since 1900 [data adapted from Chandler and Fox (1974) and United Nations (2009)]

which no fatality count has been preserved are omitted. Two things are immediately obvious from this graph: its incompleteness especially before 1600, and an approximate correlation between the instantaneous world population and the number of reported fatal earthquakes. This latter, not unexpected correlation, is readily apparent in Fig. 4, and at first sight appears to be the main conclusion of this article-more people are killed by earthquakes because there are more people living in harm's way. We shall see later that most of the world is spared fatal earthquakes, and that a dozen or so nations are responsible for the rising global death toll.

The incompleteness of the catalogue prior to 1600 means we are likely to learn statistically little by examining the catalogue before this time, hence my subsequent analysis is confined to the sixteenth century onward. Several developments occurred in human history in the fifteenth and sixteenth century that are responsible for the sudden increase in information on earthquakes and their effects. The development of printing made possible the widespread 


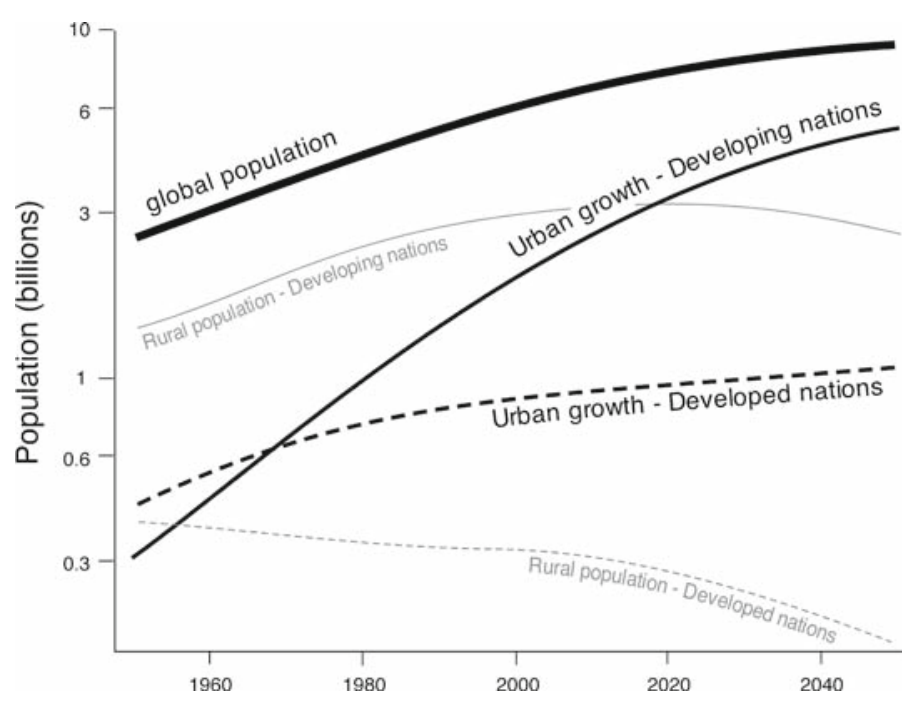

Fig. 4 Urban and rural populations in the developing and industrial nations 1950 projected to 2050 (United Nations 1999). Most the world's population recent increase has been absorbed by the doubling and re-doubling of city populations in the Developing Nations, a trend that will continue into the second half of this century

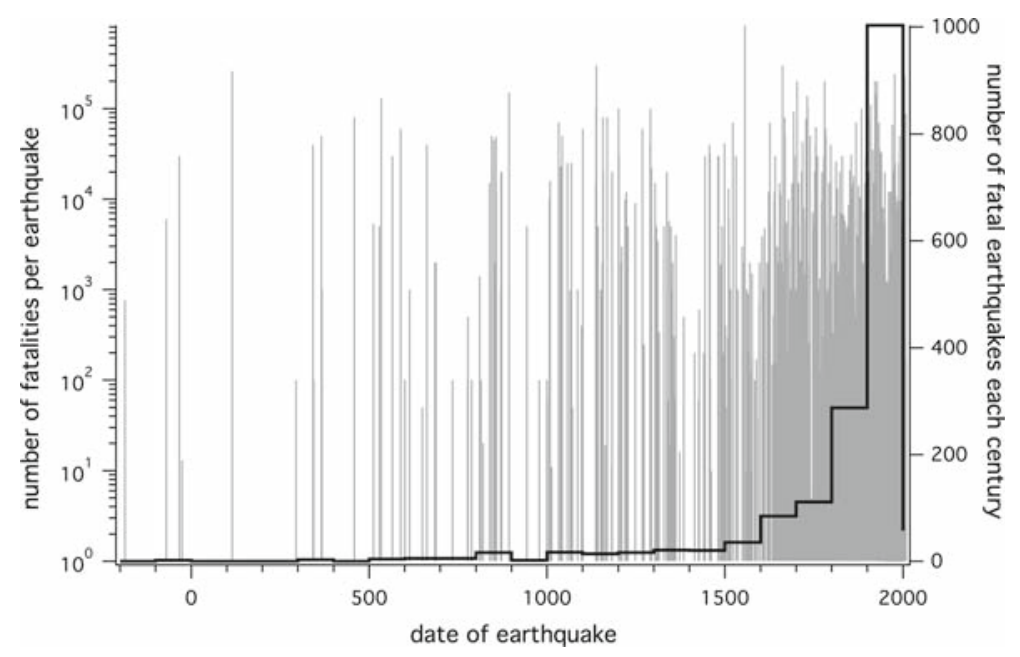

Fig. 5 Earthquakes with known fatalities. The staircase plot indicates estimated numbers of fatal earthquakes per century plotted as a function of time. The record is clearly incomplete prior to 1600

replication of travel accounts, the voyages of discovery awakened communications between Europe the Americas and Asia, with the attendant worldwide transfer of written information to and from colonies, by administrators and by individuals. Newspapers, diaries and letters home provide many first hand accounts of earthquake damage.

Figure 6 shows global trends in population and earthquake fatalities. Figure 6a suggests a correlation between the number of earthquake fatalities and world's increasing population. Figure $6 \mathrm{~b}$ indicates that globally the odds of an individual dying in an earthquake were higher in previous centuries than now (Bilham 2004). It is tempting to speculate that the implemen- 

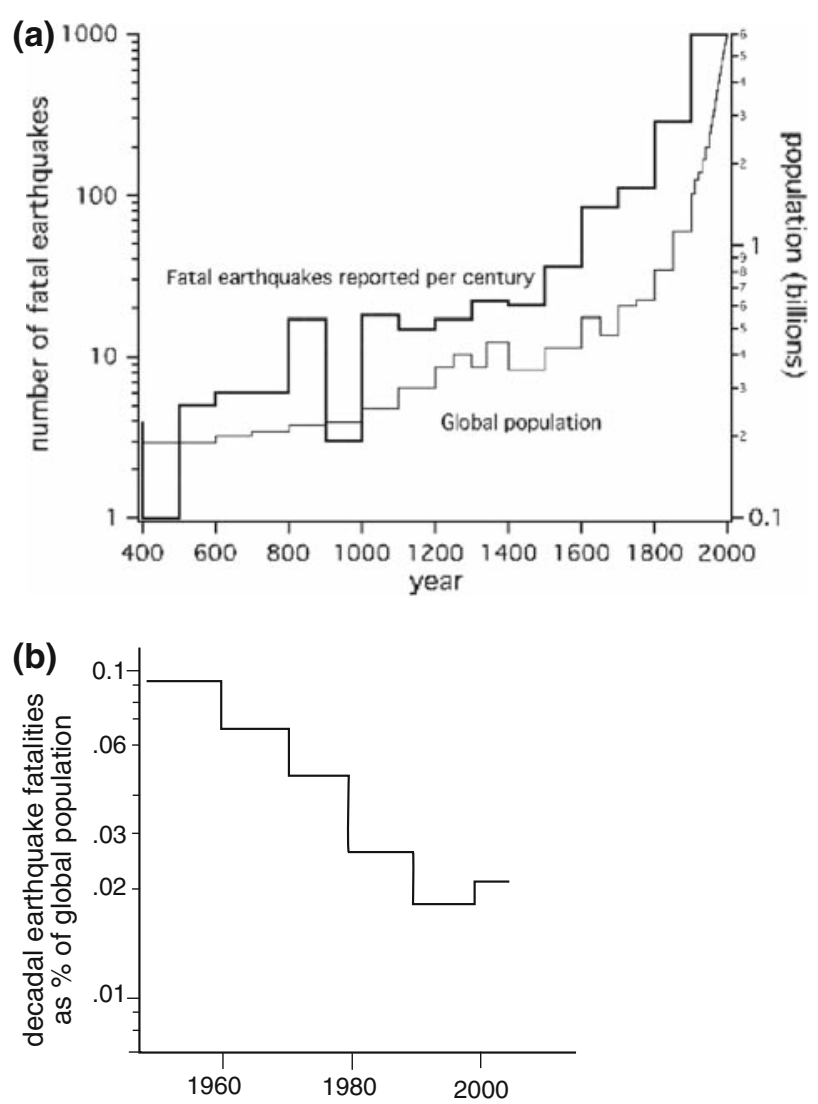

Fig. 6 a World population and numbers of fatal earthquakes per century increase steadily together. In this plot earthquakes are counted ignoring the numbers of fatalities in each earthquake ( 1 to $>100,000)$. b The number of earthquake fatalities per decade normalized to the decadal global population averaed in five decade blocks. This view of earthquakes shows that earthquake risk to the individual averaged in a global sense has reduced in recent time

tation of earthquake resistant construction methods is responsible for this decline, however, these global conclusions are unrepresentative of regional trends, for the risks to an individual vary significantly from nation to nation, and the quality of buildings stock in that country. My next section addresses this uneven distribution of earthquake fatalities and identifies those countries where city populations are most at risk.

\section{Global distribution of fatal earthquakes}

Figure 7 illustrates the distribution of earthquakes that have resulted in loss of life in the past 1,000 years. Earthquake severity is indicated by plotting a symbol whose size is represented by the logarithm of the number of deaths in each earthquake. In view of the public acceptance of the Richter scale as a measure of the magnitude of an earthquake, and public perceptions of a Magnitude-eight earthquake as something exceptional, one may define a fatality scale $M_{\mathrm{f}}$ where a fatality magnitude of $M_{\mathrm{f}}=8$ represents exceptional loss of life: 


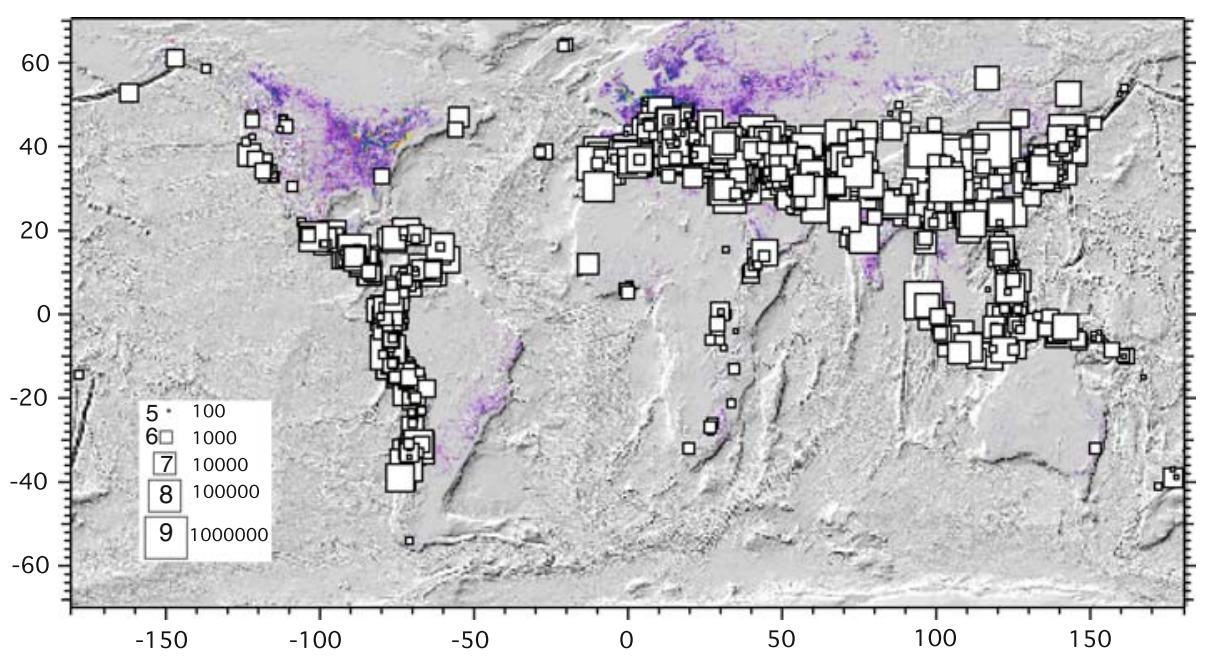

Fig. 7 The past 1,000 years of earthquakes scaled according to their fatality magnitude, $M_{\mathrm{f}}=\log (\mathrm{deaths})+3$ (data edited from Dunbar et al. 1992). About $85 \%$ of the world's fatal earthquakes have occurred in the Alpine/Himalayan collision zone from Europe to Indonesia, and $12 \%$ in the circum-Pacific including the Americas, Japan and New Zealand. The background map shows night-time luminosity of cities superimposed on global relief (Amante and Eakins 2008)

i.e. $M_{\mathrm{f}}=\log$ (fatalities $)+3$. The most fatal earthquake on record $(830,000$ deaths in China in 1556) thus would have a $M_{\mathrm{f}}$ value of 8.9 , and the minimum fatality count ( 1 death) would be $M_{\mathrm{f}}=3$, with the millions of daily earthquakes that do no damage qualifying for $M_{\mathrm{f}}=2$. A similar scale without the constant was proposed by Nishenko and Barton (1996). Neither scale has much utility, since unlike earthquake energy release, public perceptions of loss of life as a straight numerical count are immediate and direct, and their notion of logarithms somewhat hazy.

It is immediately apparent from Fig. 7 that the odds of a city being damaged by an earthquake are not evenly distributed on our planet (McGuire 2004; Dilley 2005). Twelve percent of all fatal earthquakes are found along the margins of the eastern Pacific, and fully $85 \%$ of the world's earthquake fatalities have occurred in the Alpine/Himalayan collision belt between western Europe and eastern Asia. This comparison is based on earthquakes since 1570, i.e. since the earliest historically recorded earthquakes in the Americas. Since then roughly 1,100 people have died in earthquakes each year in the western Americas and Carribean, compared to $8,900 /$ year along the southern edge of the Eurasian plate. This concentration of most of the world's fatal earthquakes occurs in less than $12 \%$ of Earth's surface area-a $150^{\circ}$ longitude band between London and Tokyo, between the equator and $45^{\circ} \mathrm{N}$.

A consequence of this uneven distribution of historically fatal earthquakes is that some nations are at much greater risk than others. In both the past 500 years and in the most recent century we are forced to the same conclusion, that a handful of nations are selectively responsible for most of the world's earthquake fatalities. In Fig. 8 the number of severe events in each country is plotted versus the severity of these events. Nations that occupy the lower left hand corner of these graphs have few earthquakes of low severity, those that plot in the upper right corner have the misfortune to host frequent severe earthquakes. The least fortunate of these countries are China, Japan, Italy, Iran, Indonesia, and Turkey. 


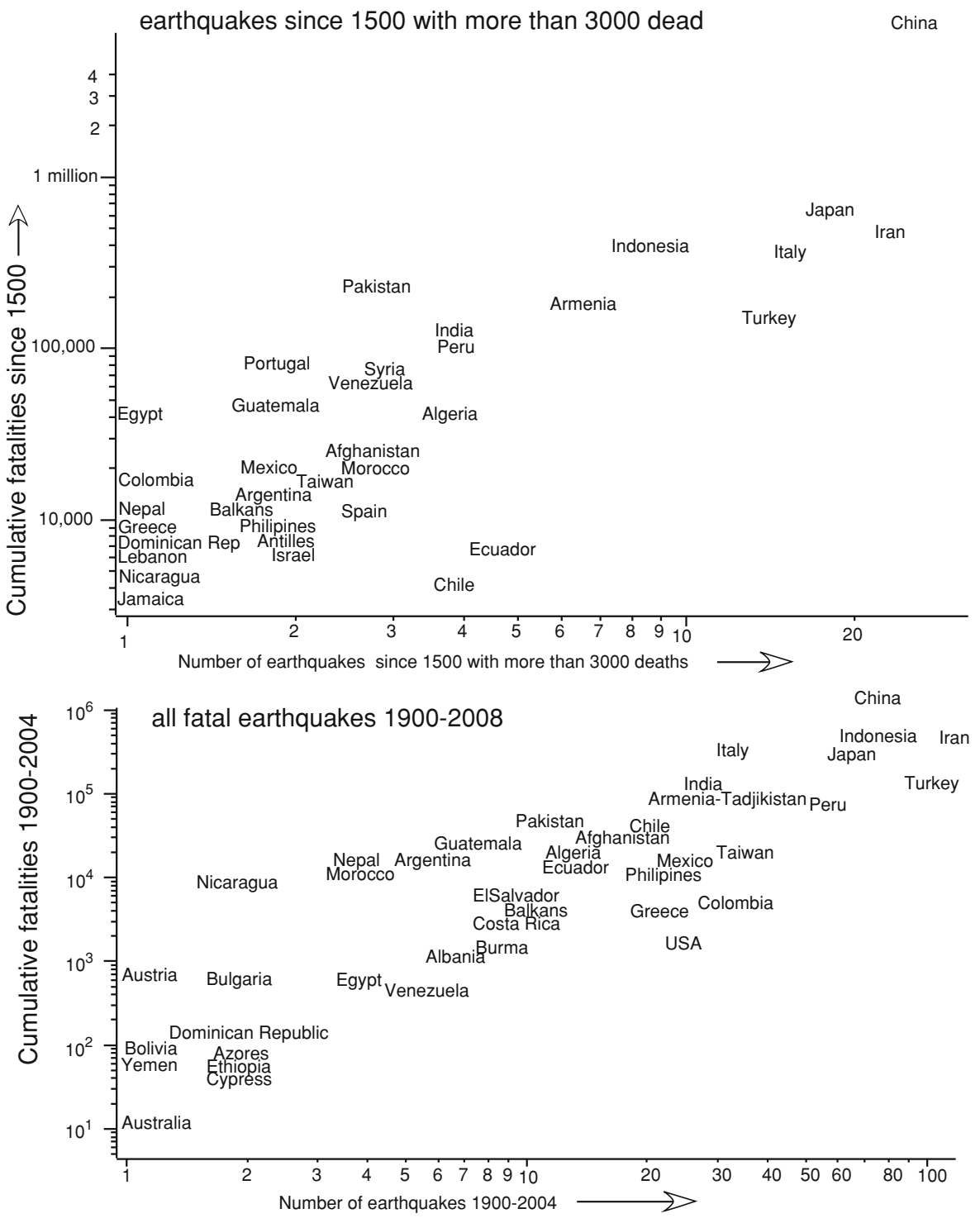

Fig. 8 In the past 500 years, and in the past century, a handful of nations can be identified that have hosted both the world's most fatal earthquakes, and greatest number of them. The lower plot includes all fatal earthquakes, whereas the upper plot includes those that have resulted in more than 3,000 deaths (updated from Hough and Bilham 2006)

Nations who lose large numbers of their citizens to earthquakes every century recognize the seriousness of the problem they face, though the response in these nations has done little to stem the rise in the number of fatalities (I later address the reasons for this). For example, the mean twentieth century recurrence interval for killer earthquakes in half of the 42 nations depicted varies from once each year, to once per decade. This time interval is short compared to the average renewal time of building stock in cities (e.g. 30 years), and in 

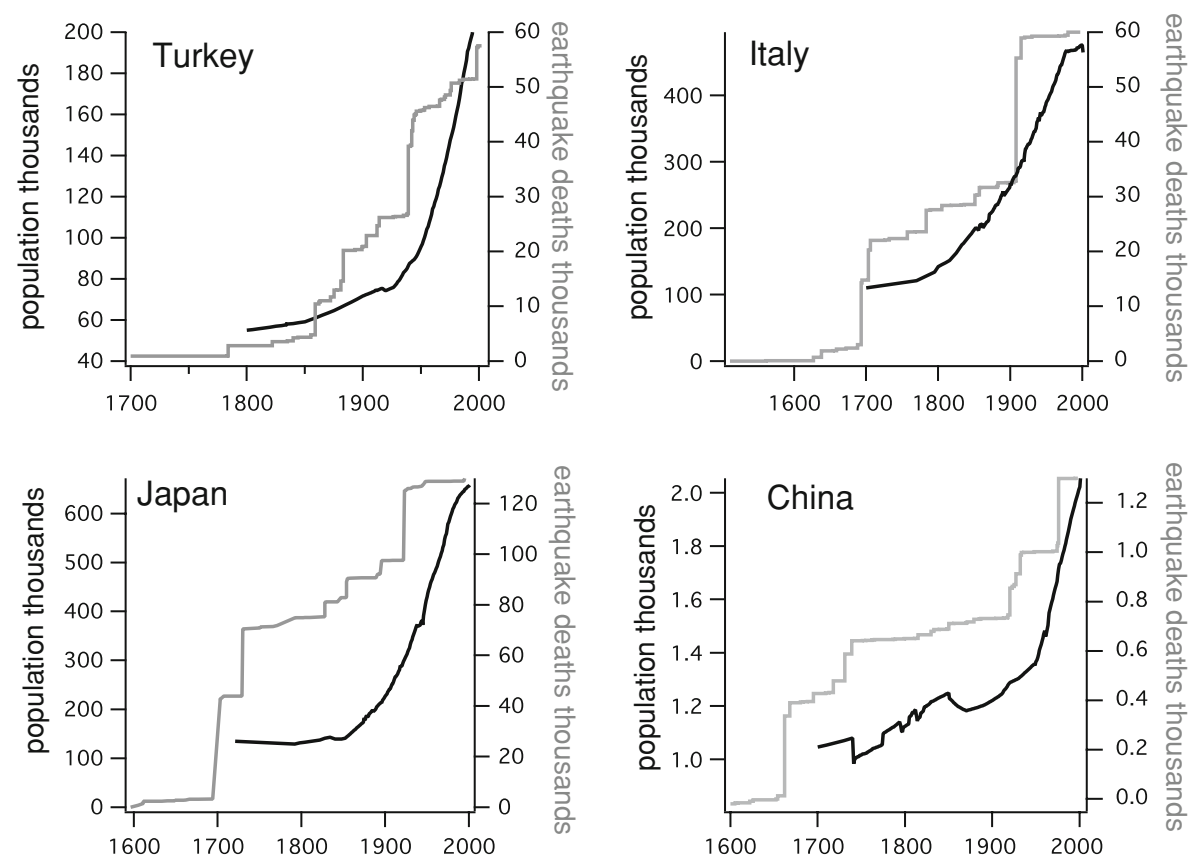

Fig. 9 Fatality rates compared to instantaneous populations in four of the nations worse afflicted by earthquakes (from Bilham 2004)

some cases is short compared to the tenure of political office in these countries (3-10years). Despite the repeated occurrence of earthquakes in twentieth century Turkey, and a remarkably well-documented historical record of earthquake disasters, a Turkish politician when interviewed publically after the Izmit earthquake $(\mathrm{Mw}=7.6$ and death-toll 17,127) voiced the opinion that the earthquake had no precedent in Turkish history. Such ignorance is surely unforgivable for an elected official. The rise in population and accompanying rise in fatalities for earthquakes for Italy, Japan, China and Turkey is depicted graphically in Fig. 9. The past 400 years of data for the four countries in Fig. 9 show that as expected, the fatality rate from earthquakes keeps pace with rising populations. The relationship though is quite erratic, dominated as it is by infrequent large earthquakes in each country. For twentieth century Iran, however, because of the remarkable incidence of fatal earthquakes, the association between rising populations and increasing numbers of fatalities from earthquakes is clear (Fig. 10). The ratio of earthquake-related fatalities in Iran to Iran's growing twentieth century population indicates the two growth curves track each other with a scaling factor $(0.3 \pm 0.05 \%)$ that changes little in the 100 years considered. This is grim statistic since it suggests that the introduction of earthquake resistant structures in the past several decades has had little effect in reducing fatalities from earthquakes. The scaling factor is large because it relates the cumulative death-toll to the instantaneous population, not the instantaneous death toll to the instantaneous population. The $\%$ fraction of the total population killed by individual earthquakes is, however, significant. For example the fraction of Iran's total population killed in the 2003 Bam earthquake was $\approx 0.06 \%$.

On a brighter note, many countries are absent from Fig. 8. Most of the African nations, the eastern Americas, northern Asia and Australia do not appear on the graph because earthquakes 


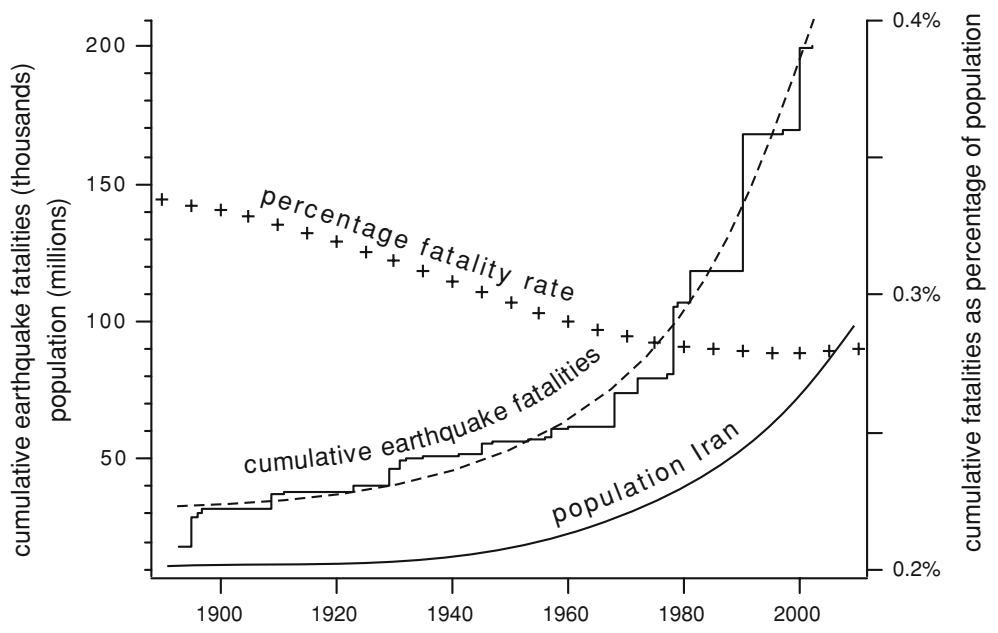

Fig. 10 Earthquake fatalities and populations in Iran. A power law is fit to the fatality data, and the population curve is a least squares power-law fit to data from Klein-Goldweijk and Battjes (1997). The percentage fatality rate curve (right hand axis) shows that the ratio of the two curves has changed little in a 100 years

there are infrequent, or occur in sparsely inhabited regions. Antarctica occupies the extreme end of the spectrum of irrelevance-few earthquakes and fewer people. Earthquakes of course do occasionally occur in these mid-continent settings and their study is undertaken with great difficulty due to their rarity and the consequent sparcity of quantitative or descriptive data. Had the multiple New Madrid earthquake sequence of 1811 and 1812, with their manythousand year recurrence interval, occurred just one or two centuries later, there would have been no speculation about the magnitudes of these earthquakes and their inter-relationships, and a much less hazy notion of an appropriate engineering response (Johnston and Schweig 1996; Hough and Martin 2002). In terms of their contribution to future earthquake losses, mid-continent earthquakes are likely to provide exceptional interest because of their uniqueness. Their infrequent historical occurrence in mid-plate settings in the eastern Americas, and Australia means that they have contributed insignificantly to the global death-toll from earthquakes.

\section{Trends in global earthquake fatality rates}

The erratic growth of fatalities with time shown in Fig. 1 prevents any simple forecast of future fatality rates. Large steps in the cumulative total are caused by occasional catastrophes that occur as a result of a "direct hit", when an earthquake occurs close to a large, poorlyconstructed city. However, if we remove these larger events from consideration we are left with well-behaved curves from which forecasts of the loss of life in these smaller, more frequent catastrophes, can be made (Bilham 1995, 2004). Figure 11 illustrates the residual curves derived from removing statistically large outliers. Two residual curves are shown, for earthquakes that cause fewer than 30,000 deaths, and for a second subset that cause fewer than 5,000 deaths.

Power law fits made to these two subsets of data (Fig. 12; Table 1) show that predictions based on early data tend to underestimate later fatality rates (Bilham 2004). Thus the global 

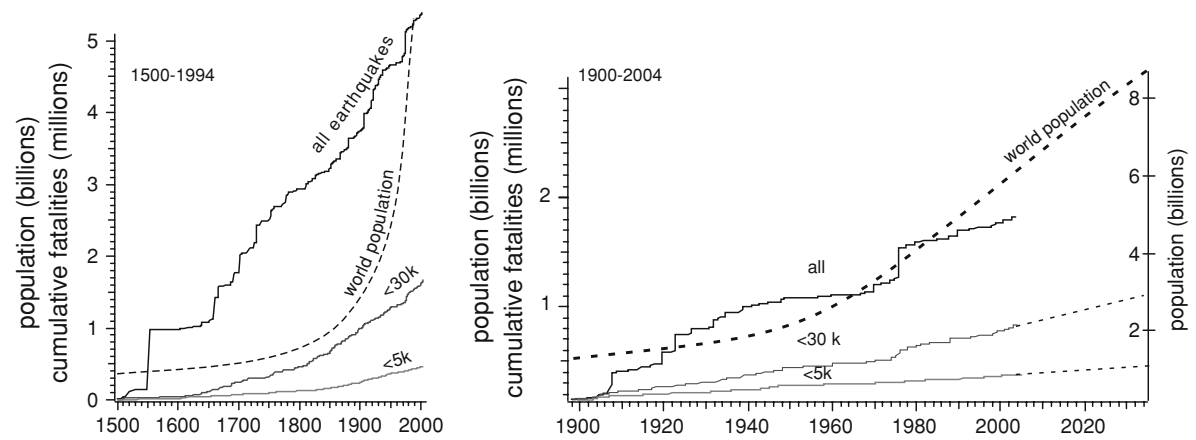

Fig. 11 Growth of fatalities with time for all earthquakes, and for subsets of earthquakes in which fatalities are fewer than 30,000, and fewer than 5,000, respectively. Forecasts based on these less extreme events made two decades ago (shaded region right) have erred on the low side

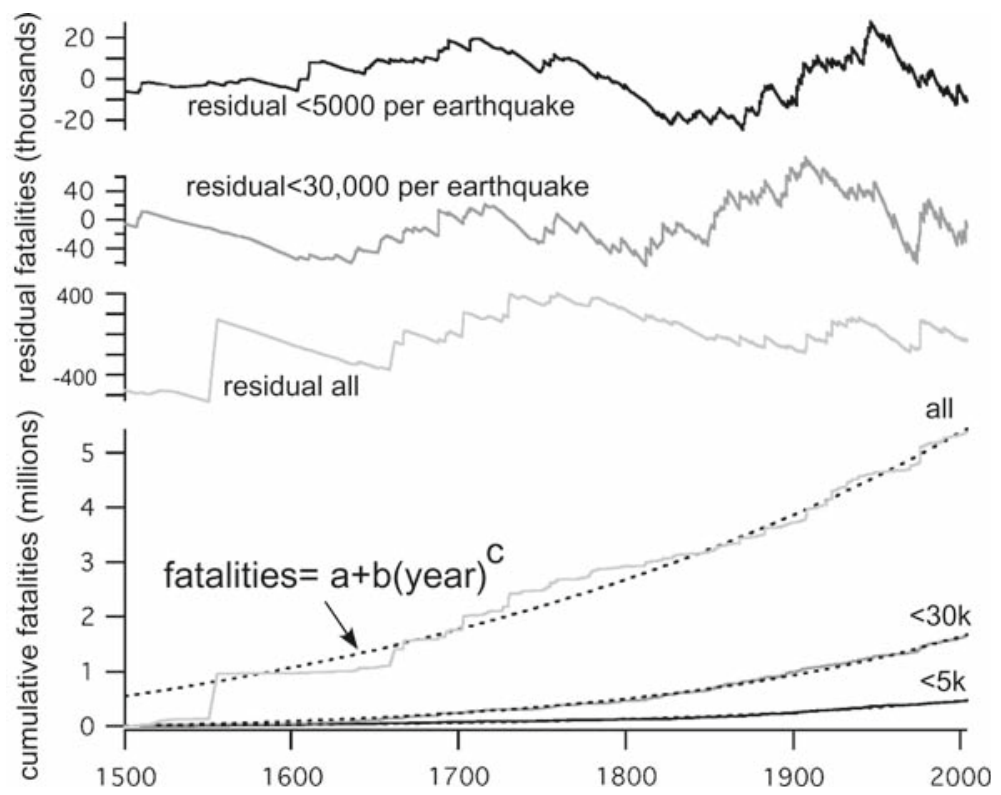

Fig. 12 Power law fits (lowest graph) and residuals to earthquake fatality data for the period 1500-1999. The parameters of these fits are listed in Table 2

fatality rate for earthquakes with fewer than 5,000 deaths per event was forecast from pre1994 data to be $2,355 \pm 130$ /year for the decade 1994-2004, and the observed rate was $2,726 \pm 50$. For earthquakes with $\leq 30,000$ deaths per earthquake the rate was forecast as $7,000 \pm 1,000 /$ year and the actual decadal average was 9,548 $\pm 198 /$ year. These are grim statistics since they appear to be conservative and robust.

If we assume a world in which earthquake resistant construction is not generally implemented we may hazard a guess at future fatalities from earthquakes. The 2000-2009 forecast for all earthquakes was for 17,094 deaths per year (Bilham 2004). The actual rate, however, was 58,000 year. If we ignore the secondary deaths in distant countries caused by the 2004 Indian ocean tsunami the fatality rate reduces to 38,000 /year, more than twice the forecast 
Table 1 Decade-interval forecasts (1900-2030) for annual fatality rate (deaths/year) based on power law fits to five centuries of data

\begin{tabular}{lccccccc}
\hline & $1900-1999$ & $2000 / 2009$ & $2010 / 2019$ & $2020 / 2029$ & $a$ & $b$ & $c \pm 0.1$ \\
\hline All & 16703 & 17094 & 17492 & 17897 & $-(6.4 \pm 0.7) .10^{5}$ & $(1.6 \pm 1.3) .10^{-12}$ & 5.6 \\
$<30 \mathrm{k}$ & 8609 & 9015 & 9439 & 9881 & $-(8.4 \pm 1.6) .10^{3}$ & $(2.9 \pm 1.7) .10^{-28}$ & 10.2 \\
$<5 \mathrm{k}$ & 2702 & 2849 & 3004 & 3166 & $-(10.5 \pm 2) .10^{3}$ & $(2.2+1.6) .10^{-33}$ & 11.6 \\
\hline
\end{tabular}

The constants $a, b$ and $c$ correspond to the power law variables in Fig. 3

Table 2 Least-squares linear fits to fatality rates (deaths/year) in successive centuries $( \pm \mathrm{SD})$ (forecasts are placed in italics to distinguish them from observations)

\begin{tabular}{|c|c|c|c|}
\hline Time interval & All earthquakes & $<30,000$ Deaths/event & $<5,000$ Deaths/event \\
\hline $1500-1599$ & & $313 \pm 31$ & $213 \pm 8$ \\
\hline $1600-1699$ & & $2,225 \pm 44$ & $578 \pm 14$ \\
\hline $1700-1799$ & & $2,098 \pm 41$ & $482 \pm 8$ \\
\hline 1800-1899 & & $5,522 \pm 33$ & $1,324 \pm 16$ \\
\hline 1900-1999 & & $6,129 \pm 36$ & $1,996 \pm 6$ \\
\hline Forecast 1995-2005 & & $6,000-8,000$ & $2,020-2,690$ \\
\hline Observed 1994-2004 & & 9,548 & 2,726 \\
\hline Forecast 2000-2009 & 17,094 per year & 9,015 & 2,849 \\
\hline Observed 2000-2009 & 52,000 per year $^{\mathrm{a}}$ & 8,320 & 1,226 \\
\hline
\end{tabular}

$\mathrm{a} \approx 38,000$ if 2004 tsunami deaths are ignored

rate. The rates for less severe earthquakes are over-estimated (Table 2). It is possible that the past decade of earthquakes represents a freak period of fatal earthquakes and that the rate will fall. I show below that this optimism may in fact be unwarranted.

\section{Fatalities and earthquake magnitude}

As a general rule the larger the earthquake the more people are killed by it. In practice the historical relationship is far from simple (Fig. 13) especially when it is recalled that population sizes have increased significantly during the past several centuries. Historical precedents permit us to conclude that $\mathrm{Mw}=8$ earthquakes near urban agglomerations can kill upwards of 300,000 people, and none at all when they occur in sparsely inhabited regions. According to Fig. 13 the upper limits for $\mathrm{Mw}=7, \mathrm{Mw}=6$ and $\mathrm{Mw}=5$ earthquakes are 40,000, 10,000 and 100, respectively. That structures collapse in $\mathrm{Mw}=5$ earthquakes is unexpected but it must be remembered that we live in a world where some structures can collapse without help from an earthquake at all. Maximum fatality counts occur for larger magnitude earthquakes when the footprint of maximum intensity shaking coincides closely with the maximum densities of population in an urban agglomeration.

Far fewer fatalities occur in similar sized earthquakes in the industrial nations than in the developing nations. The $\mathrm{Mw}=6.9$ Loma Prieta earthquake resulted in $\approx 60$ deaths (EberhartPhillips et al. 1994; Vranes and Pielke 2009), whereas the Mw $=5.7$ earthquake in Agadir, Morocco earthquake in 1960 killed more than 10,000. The Landers Mw $=7.3$ earthquake resulted in 1 death whereas the 2004 Kashmir $\mathrm{Mw}=7.6$ earthquake killed 83,000. The 


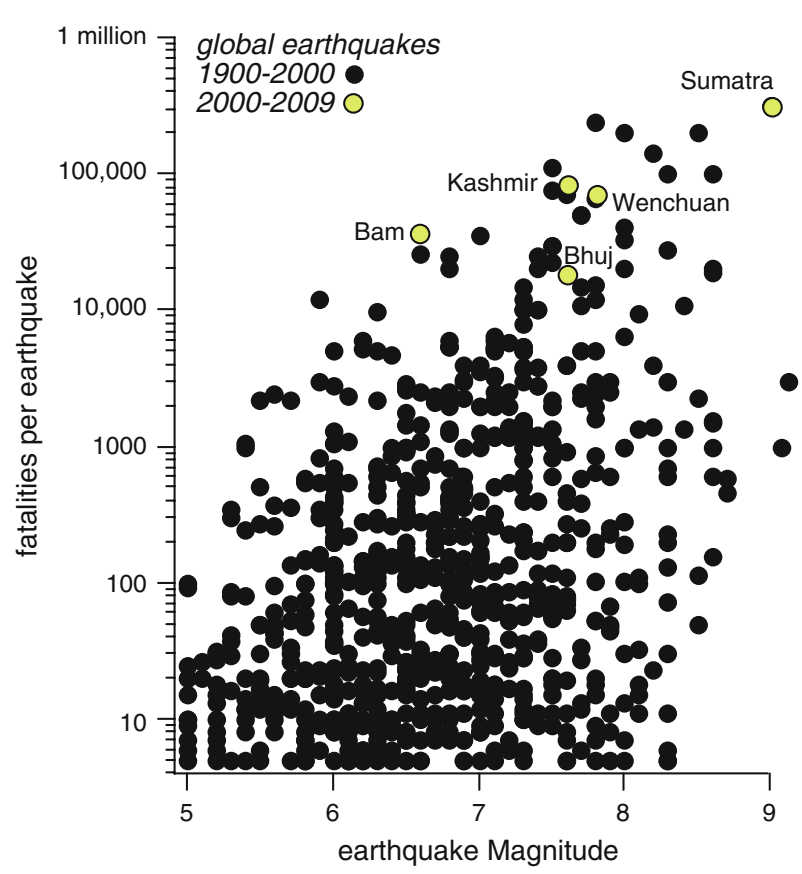

Fig. 13 Earthquake fatalities as a function of earthquake magnitude. Post-2000 large events (open circles) are named. Updated from Hough and Bilham (2006)

reasons for this remarkable contrast concern the construction methods found in different nations, and the mandatory application of building codes in most industrial nations.

\section{How bad can it get?}

The rate of occurrence of earthquakes is essentially steady but the number and size of human settlements has grown. With earthquake fatalities counts of 830,000 in our past when low populations and predominantly rural populations prevailed, what lies ahead in our future urban world? One way to approach this question is to produce computer models of scenario earthquakes, as is currently being undertaken by USGS and WAPMERR (see later section on "fatality tools"), and FEMA using the loss estimation program known as HAZUS. A difficulty with this approach is that we seek information on events that may have no precedent, and "predicted-shaking" methodologies currently require calibration events in order to hone their estimates of fatalities.

Fatality estimates have been published for cities in India south of the Himalaya for Himalayan earthquakes based on scenarios in which $\approx 150$-km-long segments of the Himalaya are proposed to have ruptured (Wyss 2005s), as is believed to have occurred in the past two centuries (Bilham et al. 2001; Bilham and Wallace 2005). Fatality counts of 150,000 are derived using the $2004 \mathrm{Kashmir}$ earthquake ( $5 \mathrm{~m}$ of slip) as a calibration event. However, prior to these most recent $\mathrm{Mw} \approx 8$ earthquakes, two or three large earthquakes occurred $(\mathrm{Mw} \geq 8.4)$, only one of which has left its trace in the historical record (Bilham and Szeliga 2008). What would happen if a repeat of one of these Medieval earthquakes occurred? The 
Fig. 14 A fractal curve for earthquake fatalities in the past 500 years shows a curve that cuts the $y=1$ axis at approximately 1 million (from Bilham 2004). The data from Iran (from Fig. 6) are shown on the same plot to illustrate that the fractal curve for different nations has similar curvature but a lower intercept than the global curve

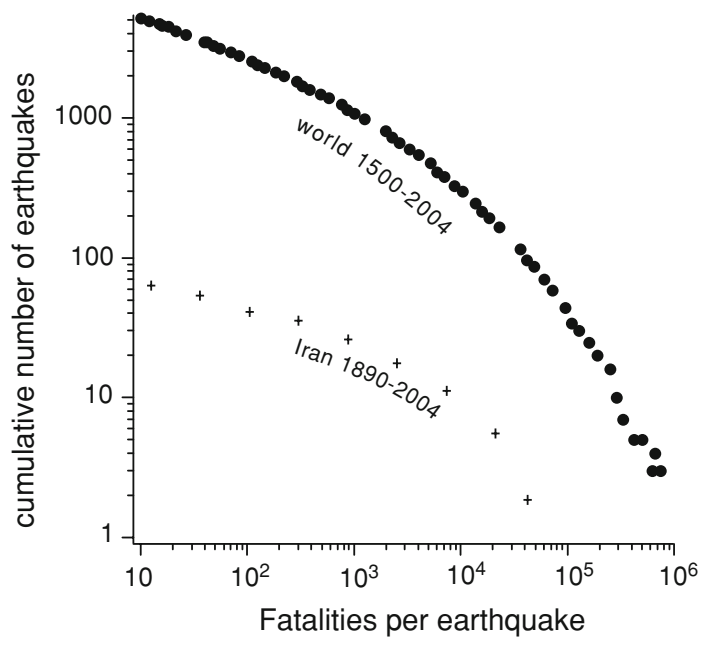

rupture length could exceed $600 \mathrm{~km}$ and the slip could exceed $20 \mathrm{~m}$. This would tend to bring the total fatality count to $\geq 600,000$ based on rupture area, a number that might easily increase by $50 \%$ based on the increased slip in the earthquake.

An alternative method to evaluate the potential fatality count of a future earthquake is to examine the fractal attributes of our existing data. This was first attempted by Nishenko and Barton (1996) who found that disasters of all kinds appeared to obey fractal distributions. The number of earthquakes that cause a given number of fatalities shows a curved relationship in the past five centuries (Bilham 2004). The curve may be interpreted in two ways: that an extreme event results in a million fatalities every 500 years with an average population of approximately 2 billion people, or that with our present global population of 10 billion people, an earthquake could result in a million fatalities every century. Century-long data from the world, or from individual nations show similar curves, but with lower intercepts (Fig. 14).

Although we might concude from the curve in Fig. 14 that once in 500 years an earthquake with a million fatalities is likely, the average population at risk for most of these 500 years was $0.5-0.1$ of the present population, and urban agglomerations in the largest cites were typically smaller than in our present-day smallest cities. With a present-day total population exceeding 6 billion, and with two dozen cities hosting populations exceeding 8 million we may reasonably anticipate an earthquake that could kill more than a million people every 100 years or so. Although such an event has not occurred in the past, never before have there been urban agglomerations of sufficient size to permit such a disaster (Wenzel et al. 2007).

A case study of the likely damage to one megacity confirms these general conclusions. Nateghi (2001) calculates that in Teheran (2001 population 10 million) more than 1.4 million deaths and 4.3 million casualties may accompany a Ms $>7$ earthquake.

\section{Strain rates, supercities and earthquakes}

From geodetic observations of plate velocities, fault slip rates and the rate of seismic moment release it is possible to calculate mean strain rates near and across plate boundaries (Haines and Holt 1993; Haines et al. 1998; Beavan and Haines 2001; Kreemer et al. 2000, 


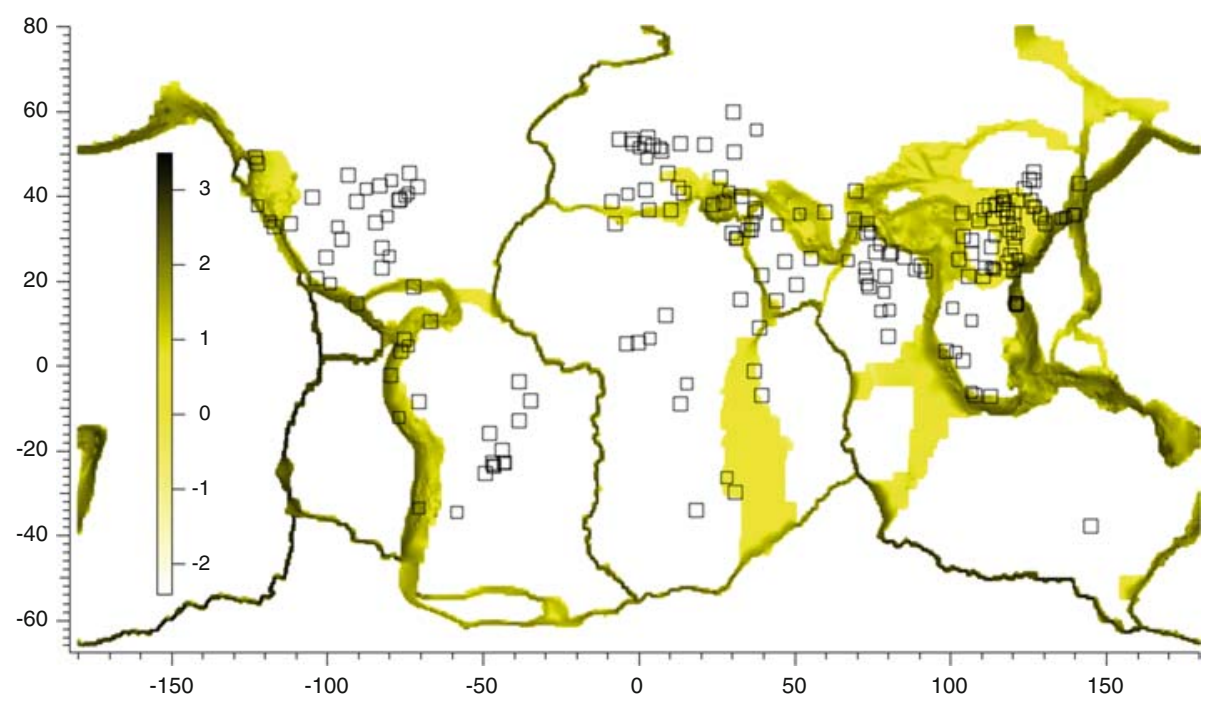

Fig. 15 The location of 194 supercities (each with a 2005 population exceeding 2 million) and their proximity to zones of high plate boundary strain rate (shaded from Kreemer et al. 2003 see also Fig. 16). The total population in these cities and urban agglomerations is 1.2 billion. Velocities of the plates are shown in a hot-spot fixed frame (Gripp and Gordon 1990, 2002). The arrow showing the motion of the eastern Pacific provides a velocity scale. The plates are named but the continents are not shown

2003). Strain rates (see Figs. 15, 17 and 18) provide a simple measure of earthquake productivity because most rocks fail at epicentral strain levels close to $10^{-4}$. Although this empirical rule-of-thumb is based on the mean geodetic strain released by an earthquake (Rikitake 1976), it lies at the heart of most earthquake scaling laws; e.g. maximum co-seismic slip of a fault $10 \mathrm{~km}$ long is typically $1 \mathrm{~m}$ (Wells and Coppersmith 1994; Scholz 2002), equivalent to a shear strain of $10^{-4}$. The rule is an approximation, and earthquakes release lower or greater amounts of slip depending on the frictional conditions in the rupture zone and the stresses released at the time of failure. However, the approximation is of utility because it provides a rough guide to the recurrence interval between successive earthquakes. A strain rate of $10^{-6}$ /year is able to renew the strain released by an earthquake in 100 years.

The areas shaded in brown on Fig. 15 are those where strain rates average $\approx 10^{-6}$ /year and in which the recurrence intervals of large earthquakes are of the order of 100-200 years. These regions of most rapid deformation occur at the world's plate boundaries. Spreading centres are rare on land (Iceland, Afar, northern Gulf of Mexico) and earthquakes there are associated with normal faulting through relatively thin elastic crust and hence typically do not exceed $\mathrm{Mw}=6$. The thickened crust, where transform faults link these spreading centres host larger earthquakes with $\mathrm{Mw} \leq 7.5$. The very largest earthquakes occur at the world's subduction zones. Here the Earth's crust is thick and the ruptures that permit the plates to converge involve areas that may exceed $1,000 \mathrm{~km}$ along the plate boundary and more than $150 \mathrm{~km}$ down-dip. The 2004 Sumatra-Andaman $\mathrm{Mw}=9.1$ earthquake ruptured a $1,600 \mathrm{~km} \times 150 \mathrm{~km}$ segment of the eastern plate boundary of India.

Typically the world's plate boundaries are relatively narrow $(<100 \mathrm{~km})$ but in some plates zones of diffuse deformation have been identified. The Indian/Australian plate, for example, is deforming in the Indian ocean causing buckling of the plate and distributed seismicity (DeMets et al. 2005). The fragmentation of the African plate along the east African rift, is 


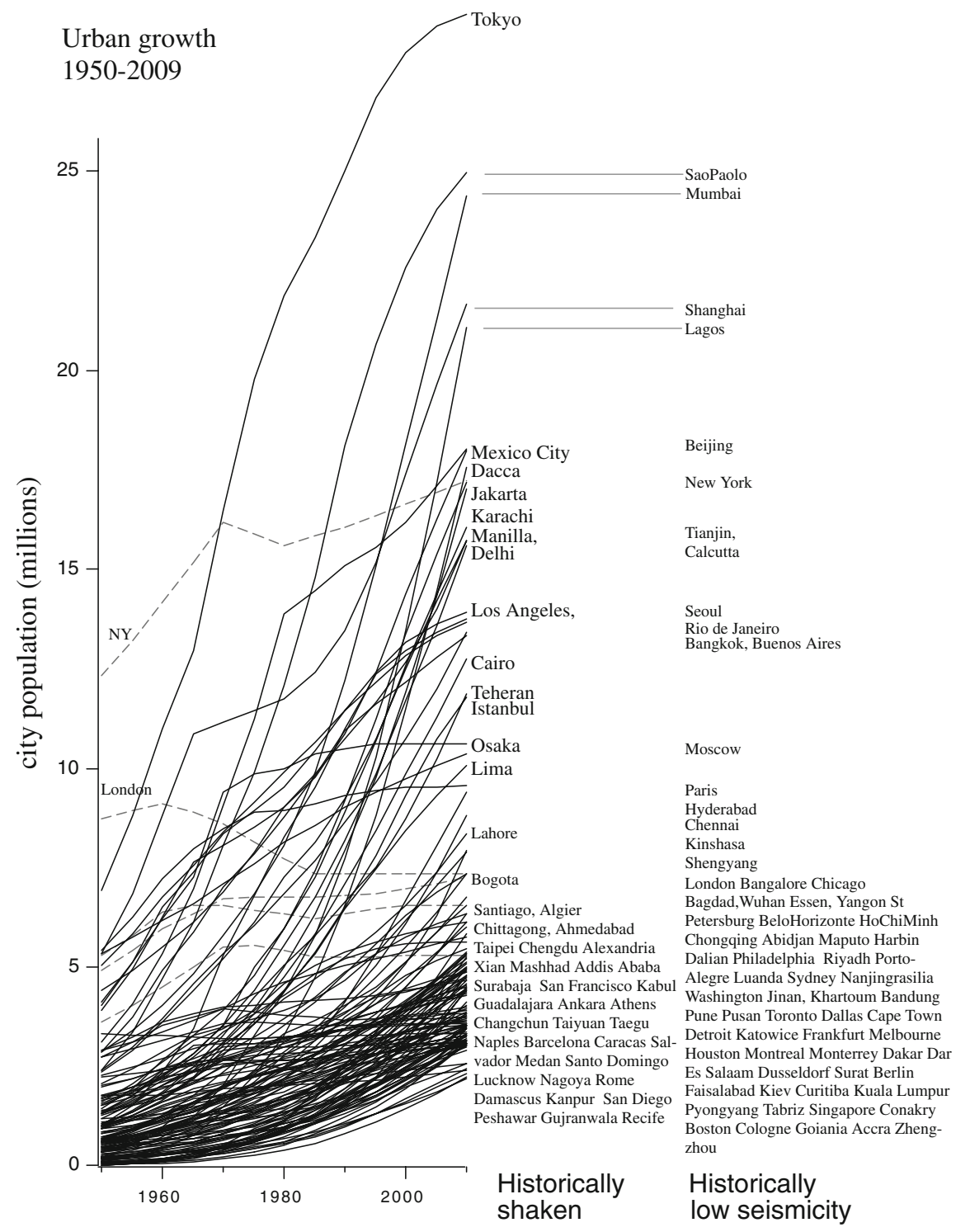

Fig. 16 The growth of the worlds largest cities 1950-2009. The cities are separated into two columns identified by whether or not historically damaging earthquakes have occurred nearby (revised from Hough and Bilham 2006). Data from the UN Population division. About $65 \%$ of all supercities (total population 403 million) are currently exposed to seismic shaking. Dashed lines illustrate the substantially slower rates of growth, and occasional decline in populations, in cities in the developed nations

typically associated with moderate and somewhat sparse seismicity ( $\mathrm{Mw}<6.5)$, but large $(M>7.5)$ normal-faulting earthquakes also occur (Jackson and Blenkinsop 1993). The frequency of damaging earthquakes in regions of distributed deformation, however, is much lower than at plate boundaries because strain rates are low, and the time taken to renew the epicentral region to failure is long. Regions of the earth where strain rates are of the order of 


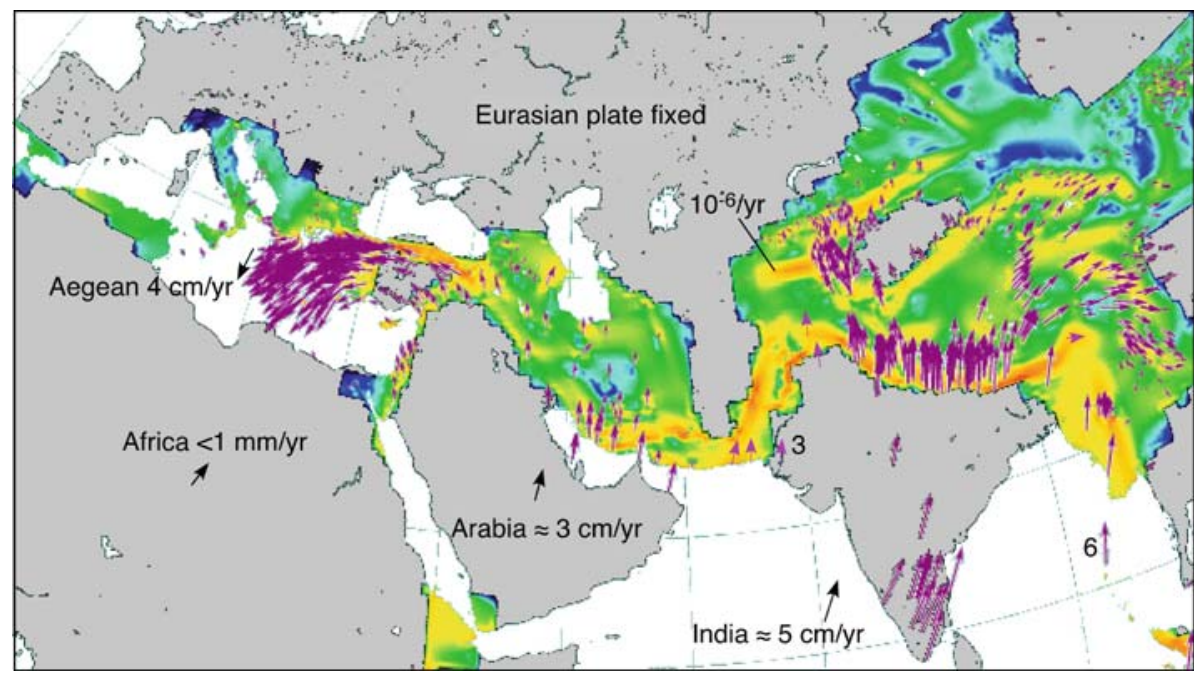

Fig. 17 Plate velocities relative to Asia show a slow northward motion of Africa, and the substantially faster approach of the Arabian and Indian plates http://jules.unavco.org/VoyagerJr/Earth. As a result of the collision, Turkey and the Aegean are rotating counter-clockwise and extruding to the SW, and eastern Tibet and Myanmar is rotating clockwise and extruding to the SE. Strain rates: blue/green $<10^{-6} /$ year, yellow $=10^{-6} /$ year, and red $>10^{-6} /$ year (from Kreemer et al. 2000, 2003). Violet arrows indicate GPS observations of plate motion, black arrows show generalized velocities
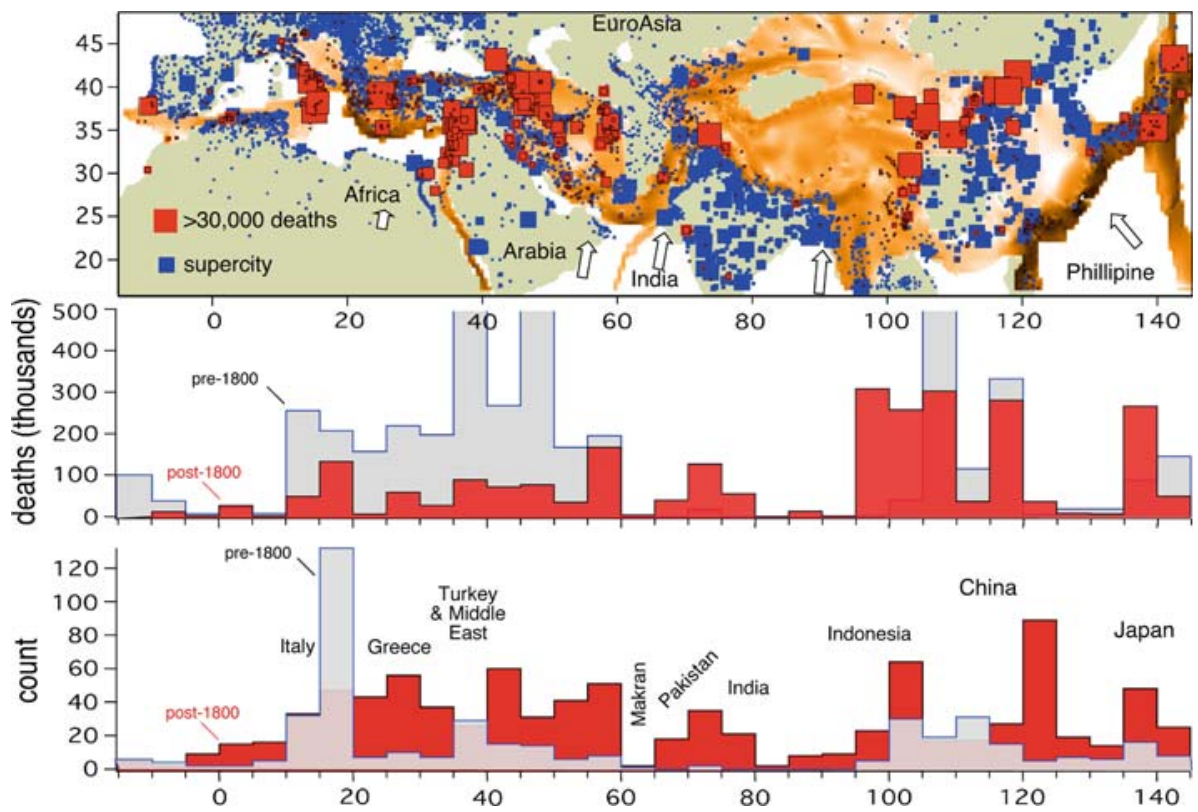

Fig. 18 Present day cities and supercities (blue) compared to earthquake fatalities in the past millennium (red), showing plates and strain rates (light- to dark-brown shading). The centre plot shows the cumulative death-toll from these earthquakes in $5^{\circ}$ longitude bins (truncated $\geq 500 \mathrm{k}$ ). The lowest panel shows the number of fatal earthquakes in these $5^{\circ}$ bins. Pre-1800 ( grey) and post-1800 (red) earthquakes are summed separately to highlight incompleteness in the data in some areas, and fluctuations in earthquake productivity in others 
$10^{-6} /$ year can be expected to produce $\mathrm{Mw} \approx 7$ earthquakes once a century. Regions where the strain rate is $10^{-7} /$ year will not regenerate sufficient strain to generate a similar earthquake in less than a millennium. This does not mean that an intraplate setting near a recent damaging earthquake will not repeatedly experience damaging earthquakes in a period of several decades. If the rupture areas of historical earthquakes are small, for example as in the Bhuj region of India, where the rupture area of the 2001 earthquake was less than $20 \mathrm{~km}$ along-strike, contiguous regions may repeatedly shake nearby towns in a time period much shorter than the renewal time of the recently-failed rupture zone.

At a global level the distribution of the world's largest cities, supercities and megacities, shows an unexpected preference for plate boundary settings where strain rates are high. More than $55 \%$ of supercities are located within $200 \mathrm{~km}$ of a plate boundary. A supercity is defined by the UN population statistics division as a city with a population exceeding 2 million. Almost two dozen of these cities now host populations exceeding 8 million, the UN qualifier for megacity status. These definitions were invoked when populations exceeding 8 million were exceptional. They are now somewhat dated given the existence of cities with populations exceeding 20 million. Figure 15 shows the present disposition of supercities relative to plate boundaries. When this global view of cities and seismic belts was depicted two decades ago (Bilham 1988) UN forecasts suggested that 40 supercities with a total population 290 million were located in seismically vulnerable locations. Of these, $80 \%$ (232 million people) were forecast to live in the developing nations. In 2005,79 supercities can be identified in seismically vulnerable settings with a total population of 472 million. About $68 \%$ of these populations are found in the developing nations, $81 \%$ of which are found the southern edge of the Eurasian plate. The total number of supercity-dwellers at risk in the cities of the developing nations is 272 million. Thus the 1988 forecast based on UN growth statistics underestimated the 2005 number by $17 \%$.

Why do cities favor seismically vulnerable locations? Cities often owe their origins to sites that are easily defended (Hurd 1903; Brunn 2003; Clark 2003). Many cities thus once started on elevated regions of coastlines or inland hills. The growth of cities, however, could not occur without advantageous supply routes and abundant water. Many of the world's supercities are ports at the edge of continents, or on large rivers. Not all continental shorelines are plate boundaries, but a significant number are, notably the circumPacific belt, the islands of the Caribbean, and some of the shorelines of the Mediterranean. Exceptions are the passive margins of the eastern Americas, northern Eurasia and West Africa, that are not plate boundaries. Another subset of supercities are located near the foothills of mountain ranges that have been formed by localized or distributed plate convergence. A mountain range brings with it the combined attraction of a trade route through the mountains and typically a supply of fresh water (Hurd 1903; Jackson 2006). Again, not all mountain ranges are active plate boundaries, but many of them are: the Alps, the Andes, the Himalaya, and the Elburz to name the most prominent. Exceptions are the eastern edge of the Rocky Mountains and the Urals.

Once established, the destiny of all settlements is to grow in size. As they grow they become part of a hierarchy of cities with a rank-ordering by population size that is established in ancient times and which is retained in subsequent centuries (Gabaix and Ioannides 2003; Taylor 2003). Hamlets and villages lie at the base of this hierarchical structure, subordinate to towns and a larger dominant city. Although the populations within the components of this city hierarchy all grow (the villages become townships, the towns become cities, and the cities become supercities), the overall ranking shows a remarkable resilience to change. Roman France has much the same city-ranking as Medieval France, which persists to the present day (Pumain 1982). 
There are few matters of greater concern than identifying those cities that are vulnerable to future earthquakes. Figure 16 illustrates the growth of supercities and divides them into two categories - those that have a known history of earthquakes and those where earthquakes in their past are sparse or non-existent. The cities so identified include some that are clearly vulnerable, and others whose vulnerability may be subject to dispute. Many cities have a tradition of earthquake damage and are unquestionably on the "hit-list": Tokyo, San Francisco, Catania, Lisbon come easily to mind. The presence of others on the "hit list" may be questioned because of their uncertain distance from a potential future epicentre. For example, Chengdu was identified as a potentially vulnerable supercity in 1988 and again in 2003 (Bilham 1988; Hough and Bilham 2006) although the city itself has no established history of catastrophic earthquakes. On 12 May 2008, however, it was shaken by the $\mathrm{Mw}=7.9$ Wenchuan earthquake whose epicentre was $80 \mathrm{~km}$ to the NW. Of the $\approx 70,000$ killed in the earthquake 4,276 lived in Chengdu.

\section{The disastrous southern edge of the Eurasian plate}

Returning now to the distribution of cities between the Mediterranean and Myanmar, China and Indonesia, a zone of seismicity that broadens eastward as it follows the southern edge of the Eurasian plate, and is responsible for $85 \%$ of the world's historical earthquake fatalities. Strain rates here are caused by the approach of the African, Arabian and Indian plates from the south towards EuroAisia at rates from less than $1 \mathrm{~mm} /$ year to rates exceeding $6 \mathrm{~cm} /$ year. The Arabian and Indian plates both rotate counter-clockwise slowly relative to Asia causing the velocity of convergence to increase eastwards (Fig. 17). Recall that a relative velocity of $1 \mathrm{~mm} /$ year applied to $100 \mathrm{~km} /$ wide zone (a strain rate of $10^{-8} /$ year) does not mean that an earthquake cannot occur, but merely that the interval between the repeated rupture of faults in earthquakes in such regions is 50 times longer than in regions where the convergence rate is $5 \mathrm{~cm} /$ year. For example, the high fatality earthquakes near Chengdu (14 May 2008) and near Bhuj (26 Jan 2001) both occurred in regions where convergence rates are slow ( $\approx 1 \mathrm{~mm} /$ year).

A striking feature of the continental collision process (Fig. 17) is the extrusion of the Aegean and Turkey to the west (McKenzie 1978), and the corresponding extrusion of eastern Tibet and Myanmar to the east (England and Molnar 1990). These two extrusion processes are almost equidistant from a promontory of the Asian plate that extends southward through Afghanistan and Baluchistan towards the Makran coast. A Mw $=8.1$ earthquake occurred at the southern tip of this promontory in 1945 (Byrne et al. 1992; Bilham et al. 2007). In the west the net result of this extrusion has been to establish substantial rates of convergence between the Aegean and Africa near Crete. In AD365 this convergence was manifest in a $M \approx 8$ earthquake that raised the western coast of Crete, and the surrounding sea floor, generating a Mediterranean-wide tsunami with huge loss of life in coastal cities (Shaw et al. 2008; Bilham 2008). Strain rates are high along the Anatolian fault and the Dead Sea rift, and these high rates have been responsible for documented destruction of cities in Turkey, Syria, Cypress, Greece and Israel since biblical times (Guidoboni et al. 1994; Ambraseys et al. 2002). Correspondingly high rates occur in the east in Myanmar but the written historical record of earthquakes here is surprisingly brief $(\approx 300$ years $)$.

Where strain rates are high, and where a 2,000 or more year record of earthquakes exists, and where city populations have been persistently large, as in Italy or the eastern Mediterranean, we find both a larger number of fatal earthquakes, and larger fatality events. Conversely, in regions where the historical record is short (India and Burma), relatively few fatal earthquakes have occurred in the historical record. This is very much a simplification 
of the various factors that influence our record of the fatality rate. For example, no account is made for building fragility, and its change through time.

The cumulative loss of life from earthquakes varies significantly with longitude, with peak fatalities in the Middle East and China. The minimum at $60-65^{\circ}$ is clearly related to the low population-density along the Makran coast, and the low rates of strain in central Afghanistan. The low cumulative fatality count in India contrasts markedly with the seismic potential of the Himalaya and subcontinent, and with the existence of large current populations. This is partly attributable to the somewhat short historical record, partly to the prevalence, until recently, of thatch and wattle-and-daub type structures, and partly due to the spatial changes in distribution of dense populations. Given the recent tenfold increase in population and the current prevalence of poorly-assembled concrete-frame structures in many of these countries, it is possible that future earthquakes in India will result in significant loss of life.

A thought experiment is of value at this point. Suppose, instead of the recent arrivals of supercities depicted in Figs. 15 and 18, that we were viewing a map of supercities that had existed for the past 3,000 years with uniform spacing. i.e. we impose in our thought-experiment steady-state demographics, and the absurd notion that our supercities were spaced evenly at, say, $50 \mathrm{~km}$ intervals for three millennia. The earthquakes that occurred near these cities in the past 3,000 years would have resulted in far more fatalities than we observe. How would the present-day fatality map appear?

The answer seems clear. There would be many more large red squares ( $>30,000$ fatalities) representing direct hits of supercities by earthquakes. It is not too difficult to imagine that the red squares in Fig. 18 would form a continuous carpet from Europe to Sumatra. A sequence of large earthquakes, as has recently occurred in Sumatra, would result in numerous additional blocks of red were this sequence to occur in the current century.

An appalling conclusion from this line of reasoning is that if we allow supercities to continue to grow from former villages and do nothing to make them less vulnerable to earthquake shaking we shall eventually attain the results of our thought experiment-a continuous $12,000-\mathrm{km}$-long swath of death and destruction. One may protest that strain rates are too low in places to fill in the blanks with earthquakes, or that some parts of the southern edge of Eurasia will never fill in with supercities. The low-strain-rate argument can be dispelled by prolonging the thought experiment to say 10,000 or 50,000 years. The present, and possibly future, absence of supercities in parts of the Eurasian belt is one that does not alter the main conclusions of this thought-experiment. Nor does a low strain rate, as mentioned earlier, prevent an earthquake occurring. If an earthquake's recurrence interval is 10,000 years and it last occurred 10,000 years ago, its epicentral process zone has attained maturity, and rupture must be considered imminent. We simply do not know how many areas like New Madrid, Bhuj or Chengdu exist on Earth.

The conclusion is obvious - that earthquake resistant construction is essential. Earthquake risk studies designed to refine our knowledge of the probability of future shaking severity of specific structures or parts of individual cities, currently represent footnotes in the general scheme of earthquake fatalities on earth.

\section{India and the Himalaya}

More than a billion people now live in India, Pakistan, Nepal, Bhutan and Bangladesh, five nations surrounded by active plate boundaries. Several studies have shown that recent earthquakes in the Himalaya have not kept pace with plate motions, and that one or more seismic gaps appear to be sufficiently mature for rupture. A surprising feature of the past two cen- 


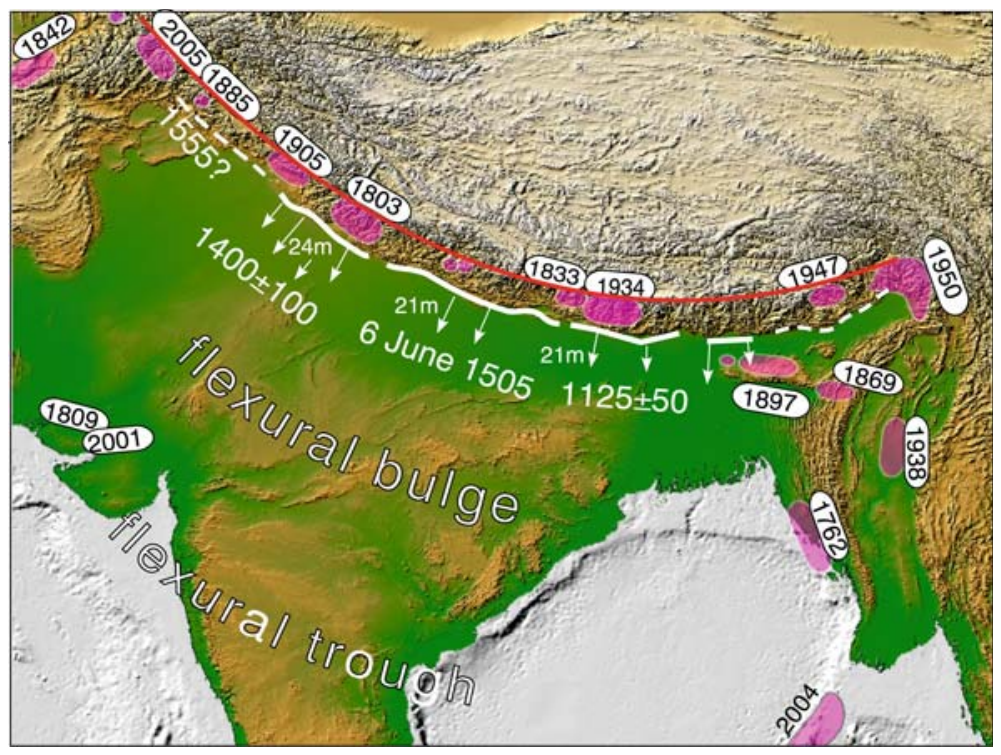

Fig. 19 Earthquake rupture zones in the Himalaya inferred from historical and instrumental records (Wesnousky et al. 1999; Lavé et al. 2005; Kumar et al. 2006). Continuous lines indicate the frontal thrusts of inferred megaquakes (dashed where inferred). Mean convergence velocity of India with Asia with Tibet is $\approx 18 \mathrm{~mm}$ /year. A flexural-bulge and outer-trough results from the depression of the leading edge of the Indian plate beneath the Himalaya

turies of earthquakes is that, with the exception of the Kashmir earthquake of 2004, none have produced surface ruptures on the frontal faults of the Himalaya. In the past decade, however, three Medieval ruptures have been exhumed (Fig. 19), two with slip of more than 21 m circa 1125 (Lavé et al. 2005) and circa 1400 (Wesnousky et al. 1999; Kumar et al. 2006). It is possible that these two events were in fact a single earthquake (Wesnousky, personal communication 2009). A distinctly separate earthquake with similar slip in western Nepal (Lavé and Yule, personal communication, 2008) occurred in the early morning of 6 or 7 June 1505 (Ambraseys and Jackson 2003). Summation of seismic moments of the probable rupture areas of these megaquakes reveals that their inclusion in a 1,000 year long average is sufficient to match the observed geodetic convergence rate of the Himalaya (Fig. 20).

Although the details of these Medieval mega-quakes have yet to be refined, in that they have ruptured the frontal faults in very long ruptures, they appear to represent the principal mode of accommodating slip of the Indian plate beneath southern Tibet. With rupture lengths of $300 \mathrm{~km}$ to more than $600 \mathrm{~km}$, and with down-dip widths of 80-95 km their moment magnitudes are significant $(8.5<\mathrm{Mw}<8.8)$, and their recurrence would pose an unprecedented threat to the cities of India in the Ganges. The renewal of 20-25 m of slip at currently observed geodetic convergence rates (16-18 mm/year) will not occur in less than 1,200 years and hence an imminent repeat of any of these three earthquakes is not anticipated soon. However, regions to the west and east that have no known rupture must be considered seismic gaps.

As an aside, it is not clear that surface accelerations during megaquakes ( $\mathrm{Mw}>8.5$ ) much exceed the accelerations associated with $\mathrm{Mw}=8$ earthquakes. For example, shaking in the Sumatra earthquake in the Andaman Islands rarely exceeded Intensity VIII above the rupture zone, despite a directivity effect caused by the northward propagation of the rupture. 


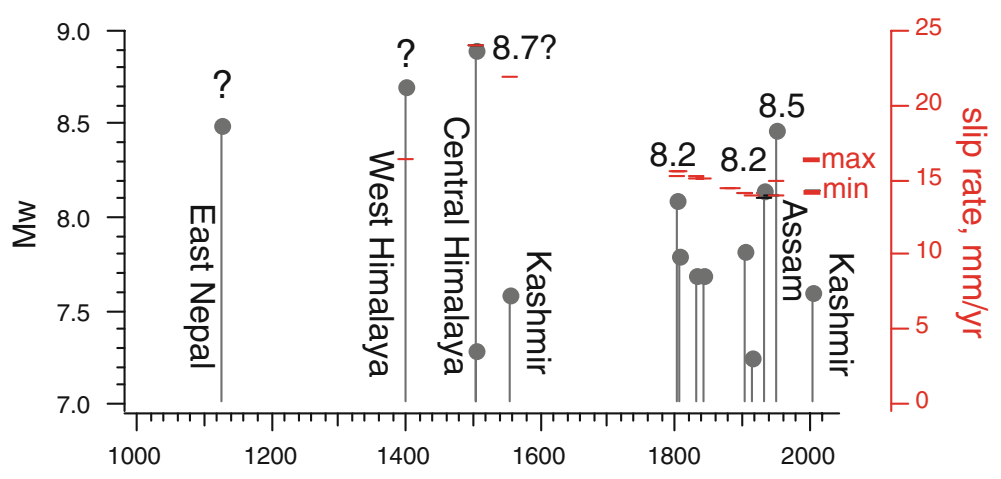

Fig. 20 Known great earthquakes in the Himalaya since $1000 \mathrm{AD}$ and horizontal tick marks indicating instantaneous convergence velocities calculated from the cumulative moment release (with summation starting 1000 $\mathrm{AD})$. The calculated minimum slip rate ( $\mathrm{min}$ ), if adjusted upwards by $20 \%$ for the numerous smaller earthquakes that have escaped historical documentation $(\max )$, is close to the observed geodetic convergence rate of $\approx 18 \mathrm{~mm} /$ year suggesting that the earthquake cycle in the Himalaya has a duration of the order of 1,000 1,200 years. The magnitudes of early earthquakes are inferred from estimated rupture lengths, that presently are very approximate

The $\approx 25 \mathrm{~km}$ depth of the rupture zone and poor spatial sampling in this island setting may have influenced the low felt intensities. However, the shaking persisted for many minutes, a feature of long ruptures that is likely to bring down structures that would otherwise survive short periods of similar intensity accelerations.

The recent occurrence of the Kashmir Mw $=7.6$ earthquake at the extreme western end of the Himalaya has raised concern that the contiguous region of the Himalaya to its east, may now have been brought closer to failure, either in a large earthquake $7.8<\mathrm{Mw}<8$, or perhaps in a great earthquake similar to those that occurred in Medieval times further to the east. The population density at risk from a earthquake in this region is large, and Wyss (2005) estimates a death toll of up to 150,000 , for a rupture length of the order of $150 \mathrm{~km}$.

The Indian subcontinent is unusual in that its collision with Asia has flexed its leading edge downwards $4-10 \mathrm{~km}$ beneath the Himalaya, causing a $400-600 \mathrm{~m}$ high flexural bulge some $650 \mathrm{~km}$ south of the Himalaya. The flexural bulge, in turn, results in a flexural trough with lower amplitude near the latitudes of Mumbai and Chennai more than $1,000 \mathrm{~km}$ south of the Himalaya. These vertical flexural displacements result in large fibre stresses of opposite sign on the surface and at the base of the subcontinent, that are omitted from the strain maps depicted in Figs. 15, 17 and 18. The presence of tensile strains at the top of the flexed plate and compressive strains at the base of the plate result in deep reverse faulting earthquakes that do not penetrate to the surface, or do so in the form of secondary normal-faulting, as occurred in the 1897 Assam earthquake (Oldham 1899). In contrast, the only known coseismic rupture mapped in the subcontinent occurred during the Latur earthquake of 1993, close to the outer flexural trough (Jain et al. 1994; Seeber et al. 1996).

The flexural stresses caused by bending the thick Indian continent far exceed those needed to generate earthquakes, but it is important to realize that the stress system is not static. The Indian plate is mobile, whereas the stress field is "fixed" to the Himalaya. As a result, the $2 \mathrm{~cm} /$ year descent of the plate beneath Tibet results in slow rates of change of flexural stress throughout the plate. The maximum rates of change are slow e.g. 1 bar per millennium (Bilham et al. 2003). Earthquakes have been known to be triggered by a few bars of additional stress. In contrast the spatial gradient of surface stress exceeds more than $2 \mathrm{bars} / \mathrm{km}$ 
in places. This means that there are many regions in India that lie on the brink of failure, where slowly increasing compressive or tensile stresses from India's plate mobility will give rise to apparently random distributions of earthquakes, possibly similar to the distributions we have witnessed in the past few 100 years. A flexural stress regime is unlike the familiar plate-boundary setting in which seismologists may anticipate earthquake renewal times associated with a recurrence interval and its uncertainty ( $n \pm m$ years) linked to the plate boundary displacement rate. The displacements associated with flexure are limited $(<10 \mathrm{~m})$, and vary in space and time, and, over sufficiently long periods of time, change their polarity.

A consequence of this flexural stress regime is that many of India's urban agglomerations, which lie far from the reach of Himalayan earthquakes, are exposed to shaking from earthquakes throughout the subcontinent. These earthquakes are typically small, but occasionally, as we have seen in the past few decades, they have magnitudes in the range $6<\mathrm{Mw}<7$. The assessment of seismic risk to these cities is thwarted by the brevity of the historical record of Indian earthquakes ( $<400$ years) and by the almost complete absence of surface faulting from which an alternative seismic history can be evaluated (Bilham 2004). Almost the only method available for adding to our knowledge of early earthquakes here consists of searching for paleoseismic liquefaction features.

\section{Hair-trigger estimates of imminent and ongoing destruction}

Global seismic networks can typically locate and size an earthquake within 20 min anywhere on earth. Local networks vigilant for nearby damaging events can often do the same in as many seconds (Kanamori et al. 1997; Wald et al. 1999).

The ability to detect an earthquake and to forecast its shaking intensity as a function of distance from the epicentre within $20 \mathrm{~s}$ of the mainshock, permits early warning of the arrival of destructive surface waves originating more than $\approx 70 \mathrm{~km}$ from a city. A technical difficulty in implementing successful early-warning algorithms is that not only must one record the earthquake from a sufficient number of seismometers to determine its location, but one must also develop reliable ways to estimate the magnitude of the earthquake early in the rupture process. For a large earthquake the rupture may take 10-60 s from start to stop, and the problem becomes one of distinguishing a small earthquake from a larger rupture from an interpretation of clues in the early body waves.

Early warning systems have been implemented in California, Mexico and Japan, and have application in many more locations, e.g. to cities and power plants south of the Himalaya. Insofar as large amplitude seismic waves from a nearby earthquake will cause damage whether or not they are known to be on their way, early warning systems are an admission of defeat for most earthquake engineers and city planners. The city is destined to be shaken either way. Warnings of imminent shaking, however, do have utility in such applications as slowing trains, closing overpasses and tunnels, switching hospitals to emergency power and switching critical facilities into failsafe modes. Whether or not such schemes have broadcast value to the inhabitants of cities depends on the level of preparedness of the population to alerts, which usually requires practice drills. In Mexico lives have been lost from false alarms caused by alerting populations in Mexico City to the arrival of surface waves from the Pacific coast, whose amplitudes have on arrival proved non-threatening to structures.

A successful development in the past decade has been the development of computer generated scenarios of destruction within 20-30 min of an earthquake anywhere in the world (Nichols and Beavers 2003; Wyss 2004; Allen et al. 2009). The programs are known by 
their acronyms PAGER (Prompt Assessment of Global Earthquakes for Response) implemented by USGS (http://earthquake.usgs.gov/pager/), and WAPMERR (World Agency for Planetary Monitoring and Earthquake Risk Reduction) implemented by a non-profit scientific organization in Geneva (http://www.wapmerr.org/).

The products of these programs are maps and lists of probably damaged cities, and quantitative estimates of the numbers of people exposed to different severities of shaking by a recent earthquake, within $30 \mathrm{~min}$ of its occurrence. In some cases the number of deaths and casualties can be forecast with reasonable precision $(<20 \%)$. These data are eagerly sought by relief agencies that are mandated to organize appropriate levels of response, and to divert relief supplies to critical areas in the aftermath of the earthquake. Following a major earthquake it is not unusual for administrative centres to lose all communication with the epicentral region and to be unable to assess the areas in most need of relief. WAPMERR and PAGER provide this essential information.

Once an earthquake occurs and its magnitude, depth and location are quantified, a computer generates a shaking intensity map based on generalized attenuation laws, or if known, site specific attenuation and microzonation information. The computer then searches a data base of settlements surrounding the epicentre. Based on information on the vulnerability of structures within these settlements, and the known population density, a calculation of the predicted number of a fatalities and casualties can be made using an empirical scaling factor. The methods work well where numerous earthquakes occur because this scaling factor can steadily be refined.

It should be noted that not all deaths in an earthquake are instantaneous. Numerous casualties die in the days following an earthquake from renal failure and other complications (Seligson and Shoaf 2003). PAGER and WAPMERR thus serve a vital role in minimizing fatalities from earthquakes.

\section{Seismic futures: three final decades of boom construction 2010-2040}

In 2008 the population of the urban population of the world for the first time in history exceeded the rural population. A final doubling of world population is anticipated to occur in the next half century following which populations will stabilize and possibly decline. In the context of urban engineering the number of dwelling units in the world doubled between 1950 and 2003 and is expected to have double again by 2030. More dwelling units were built in the past 70 years than at any time in Earth's history, and the number continues to rise. We live in the age of construction on our planet (Hough and Bilham 2006; Tucker et al. 1994). Most of this new construction will occur in the cities of the developing nations, and most of it will occur in cities whose present populations are less than a million.

We have seen that fatalities from earthquakes -2 million in the past century, and more than half a million in the past decade-have not occurred evenly on earth. About $85 \%$ of all fatalities occur along the southern edge of the Eurasian plate, with roughly $12 \%$ occurring on the western edge of South and North America. Fatalities from earthquakes in a handful of nations located in the developing nations of these "death-zones" appear to have kept pace with rising populations despite the application of earthquake resistant construction in the past few decades. The current generation of earthquake engineers, city planners and political leaders have an unprecedented opportunity to render many of the world's cities resilient to earthquakes. It is clearly happening in the developed nations, but will it occur as successfully in the places under greatest threat? 
It is almost impossible to believe that mankind will continue to construct cities that are vulnerable to shaking. However, I am not optimistic that there is sufficient awareness, or determination, to make this happen during the current building boom.

\section{Acceptable risk: computations vs. human nature}

Perceptions of risk are surprisingly pragmatic. The annual global death toll from earthquakes $(<50,000 /$ year, $\approx 137 /$ day, since 1999$)$ is less than those killed globally in road accidents [>1 million/year, $\approx 3200$ each day, Peden (2004)], yet the few people who have considered the odds of dying in a road accident do not desist from driving their cars on a daily basis.

There is no question that engineers know how to construct buildings that can survive the strongest shaking, and to optimize the seismic resilience of a structure for a given construction cost. Clearly-defined paths are followed by engineers at the design stage where decisions are made on the incorporation of structural features to a level of safety appropriate to the level of acceptable risk. What constitutes an acceptable level of risk can be considered a policy decision, or a societal decision (Waugh 1998; May 2001). It is invariably a decision where increased safety of a building results in increasing its cost, but the assessment of what constitutes an acceptable risk varies significantly.

The assessment of seismic risk has now attained a level of sophistication that to many is baffling in its intricacy. The starting point is an assessment of the seismic productivity of a region based on a historical data base of previous earthquakes. From the estimated return periods of these earthquakes the odds of an earthquake at a certain distance from the proposed structure are calculated for the design life of the building-usually 30-50 years. Then follows an assessment of the attenuation of seismic waves and/or their local amplification by site specific effects. The analysis is accompanied by assessments of the spectral-period, amplitude and duration of these anticipated waves to determine velocities and accelerations to which the proposed structure will be exposed. Cornell (1968) summarized the seismological starting point of this analysis "This information is transferred from the seismologist in the form of his best estimates of the average rate of seismic activity of potential sources of earthquakes, the relative likelihoods of various magnitudes of events on those sources, and the relationships between site characteristics, distance, and magnitude applicable for the region".

The return time for earthquakes of various magnitudes in a given region is always subject to uncertainty, and the quantification of this uncertainty is an issue of great importance. It is easiest undertaken where seismicity is abundant and statistics can be developed based on large instrumental data bases (e.g. in California and Japan), often refined by successive case histories. Plate boundary regions in the Industrial Nations are also endowed with an abundance of data on mapped surface faults, on which recurrence rates, slip rates and regional strain fields may supplement and extend the instrumental catalogue.

In places where seismicity is sparse, the quantification of uncertainty becomes more elusive, and quite diverse opinions may exist as to the magnitudes of former earthquakes, their locations, and the appropriate attenuation versus distance equations to be applied. The introduction of a logic tree analysis to quantify these opinions brings with it certain new dangers. The most outrageous opinion can be permitted in such an approach, as long as it can be appropriately weighted. But the difficulty with this is often deciding on an appropriate weighting (Krinitzsky 1995). An opinion about an opinion is increasingly removed from being a quantitative measure of uncertainty. 
Observational uncertainty is classed as epistemic if it has the future potential to be reduced by the discovery of new ways to quantify the effects of ancient earthquakes, or to incorporate the results of recent earthquakes. Epistemic uncertainty may be reduced by the discovery of hitherto unknown historical archives, or may be improved by the more precise estimation of attenuation in a region etc. The statistical treatment of these data in order to predict building response results in aleotoric variability. Aleotoric variability is intrinsic to the mathematical estimation of shaking probability and cannot be reduced by future discoveries. The combination of these two layers of uncertainty, with or without logic tree analysis, provides some of the most reliable methods available for assessing future probabilities for shaking (e.g. Porter 2003; Thenhaus and Campbell 2003).

These approaches reduce the complex procedures of using uncertain historical data to forecast a probabilistic, but quantified future, almost to the level of a cookbook. More often than not a specific computer program is invoked into which data are entered and from which an authoritative report can be published. There is much to be said for unification of procedure in this way, but some scientists view the resulting forecasts with suspicion, or at least caution.

Analytical uncertainty is most problematical in regions where urban growth has recently expanded to areas where historical seismicity is sparse. The absence of data may force the engineer to accept a level of risk over what may elsewhere may be considered normal. A recurring theme concerns the wisdom of using a several-decade period of instrumental data on which to base forecasts. Were a seismologist consulted about what constitutes a suitable period of instrumental data on which to base future forecasts, his/her answer $(1,000$ 10,000 years) may appear ridiculous to an engineer pressed for immediate details.

Statistical methods provide a comforting layer of mathematics between the obvious problem ("I am told that my proposed building may collapse in a future earthquake") and the money ("what is the minimum additional cost needed to protect my investment in this structure?"). The issue is usually posed in terms of economic losses rather than potential fatality count.

However, the real problem in the Alpine/Himalayan/Indonesian death zone is much simpler. Structures throughout this region exist, or are currently under construction, that are more or less guaranteed to kill their occupants. Earthquake-resistant construction is absent in these killer buildings and despite the good intentions of the engineering community, there is no plan, nor much hope of fixing these buildings before their collapse.

In order to assess the true seismic risk to our future cities I suggest we stand back from the details of risk assessment and return to some fundamental problems of human nature that in practice circumvent the careful deliberations and action-plans of earthquake engineering. If we do not do so, we are in danger of not seeing the wood for the (logic) trees.

Anyone who has recently strolled through a modern city "become an heap" following an earthquake will have noticed repeatedly the same types of damage. City construction is now almost ubiquitously weighted towards concrete skeleton construction. Damage to concrete frame structures is rarely caused by incorrect design. It is typically caused by incorrect assembly_weak concrete, brittle steel, an absence of stirrups, or a lack of through-going steel-work at columns. Where construction codes have been implemented such damage is rare. Problem assembly can usually be traced to ignorance on the part of contractor, or home owners trying to save money at the construction stage. Construction guidelines exist in all of the nations afflicted by earthquakes, but it is not unusual for these guidelines to be ignored by builders determined to save costs.

Thus while the engineering community can design the world's cities for a safe future defined by specified levels of risk, the safety of cities in many parts of the world often depends on factors beyond the control of the engineer. I list a few of these below. 


\section{Fatal flaws in attempts to reduce seismic risk}

The following is a list of potentially fatal flaws in our present day application of earthquake risk reduction. It is by no means exhaustive and not all of the problems identified are applicable to all countries. Some are corrupt practices, and others are incorrect assumptions. All can be ascribed to ignorance in one form or another. The first four are intrinsic to the methodology of earthquake risk assessment. The remaining dozen items listed are issues that are rarely considered in risk estimation, but in the developing nations are responsible for current weaknesses in the implementation of safe housing:

False Assumption \#1. Seismic hazard maps or maps of seismic risk indicate the probability of future shaking intensity.

Seismic hazard maps are maps of the past! They represent an image of future shaking only where two further assumptions are applicable - that the rate of seismic productivity does not change with time, or that the history they represent is sufficiently long to reveal all possible earthquakes. This last assumption is equivalent to stating that the instrumental record, the historical record, and the paleoseismic record, sample the seismic cycle and its fluctuations in a region. These conditions are met with only in a few areas on earth.

False Assumption \#2. The most recent seismic hazard map is the most reliable available.

While a revised map is often driven by a well-intentioned need to revise estimates of seismic risk, it may in fact represent a map of the least-likely locations to be next visited by a damaging earthquake. This curious circumstance arises when an earthquake in an unexpected location generates a bulls-eye of seismic hazard contours (usually contoured red and orange), that are added to a part of map that hitherto included shades of pastel hues indicating low seismic hazard potential. The occurrence of this rare earthquake usually means that the elastic energy in that region is now spent, and the next most-likely location for an earthquake are the contiguous pastel regions near the bulls-eye. An example of this readjustment of the hazard and risk maps occurred following the Jabalpur (22 may 1997) and Latur (30 sept 1993) earthquakes in India.

False Assumption \#3. If sufficient funds and people are focussed on a local seismic risk problem, a reliable data base of historical data can be compiled to calculate probabilistic forecasts of future seismicity.

Major urban and industrial developments have recently been established in areas of littleknown seismicity, where the engineer is likely to be forced to accept poorly researched, or poorly constrained, predictions of potential future seismicity. On these occasions the engineer may place an urgent demand for new data from seismologists and historians who may have none to offer. Throwing money at the problem may thus be futile. Archival research cannot be hurried, geodetic deformation measurements require time to elapse between first and last measurements, a year or two of instrumental seismic data is unlikely to clarify the historical seismic record, and may in fact distort it. The result of an expensive, hurried investigation is that it may provide an apparently authoritative view of an intrinsically uncertain region of seismic risk. One very specific danger in focussing a task force of scientists on an area that may be new to them (often the setting of an international-aid project), is that their starting point will be an archival research of previous contributions to that area, which, as we have seen earlier, is likely to incorporate the cumulative historical errors and deficiencies of previous catalogues. Rarely will members of this team have the time (or language skills) to read and expand the original source materials. Worse, a group of incompetent people may be commissioned who are new to the field entirely, but who will nevertheless produce a report, which from its thickness, or from the glossiness of its presentation, may to the commissioning body convey the authority they seek. What constitutes an acceptable risk in circumstances where 


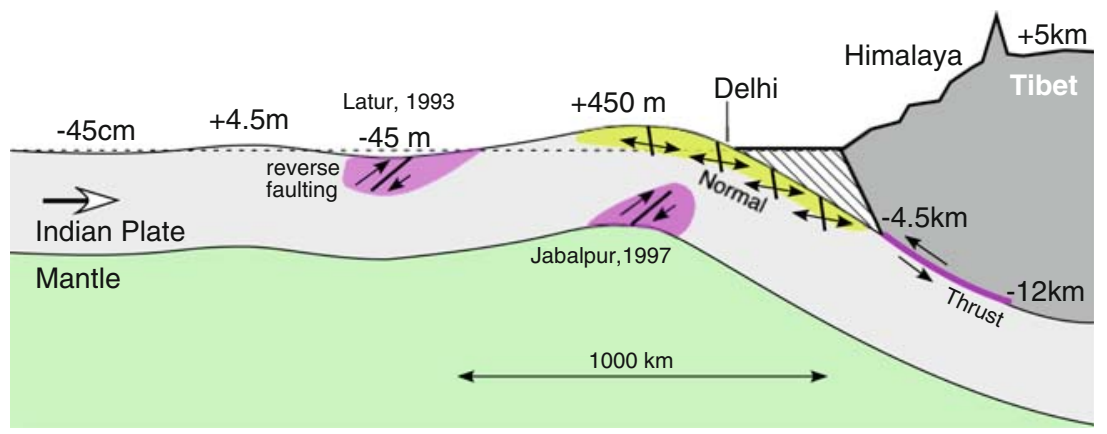

Fig. 21 Schematic view of the flexural geometry of the Indian plate showing the styles of faulting caused by bending stresses. The flexural stress field is fixed in space, but the Indian plate streams northward through it at a rate of approximately $2 \mathrm{~cm} /$ year. As a result many parts of the plate are approaching failure while others are receding from failure (Bilham 1995)

data are sparse, may require a certain amount of informed judgement and experience, rather than acceptance of a numerical result from a probabilistic treatment of shortterm seismicity data.

False Assumption \#4 A global view of earthquake risk will improve our understanding of local seismic risk.

The assumption may be true in an actuarial sense, but breaks down where the local tectonic setting may differ from a recognisable global norm. A case in point is the tectonic setting of mid-plate India, one of the few regions of the world where a huge population (1/6 of the current world population) lives on a flexed plate. The recurrence interval of earthquakes here may exceed 100,000 years, and there are no obvious faults on which to focus paleoseismic studies (Figs. 19 and 21). The historical record, which should extend back to the invention of writing, is sparse before the time of Vasco da Gama, and becomes detailed only after 1800 . It would be misleading to think that results from a global initiative to characterize seismic risk (e.g. GEM or GSHAP) can do justice to a physical process whose rupture modes have been sampled so sparsely in the historical or instrumental record.

The above issues are technical problems that weaken the foundations of probabilistic risk assessment. I now list a number of issues related to societal governance problems in certain developing countries, whose effects on the implementation of earthquake resistance are often not considered.

False Assumption \#5. Elected politicians are knowledgeable of the earthquake histories of their countries.

Many politicians rise to power from disciplines that require no knowledge of the history of their country. Some politicians appear to lack even a rudimentary education of any kind.

False Assumption \#6. Politicians will act responsibly when provided with estimates of seismic hazard.

The term of most democratically elected officials rarely exceeds $1 \%$ of the return time of most plate boundary earthquakes. They may not understand probability theory but they are adept at a calculating whether an earthquake is likely to happen during their tenure. As part of the prioritizing of the importance of earthquake resistance, a politician may mentally prepare escape clauses for feigning ignorance should an earthquake occur. As a result few politicians have the vision or motivation to push the enforcement of earthquake resistant codes ahead of more pressing issues for which they may be responsible. 
False Assumption \#7. Tenders and sealed bids to avoid corrupt selection practices, guarantee safe construction.

Many administrative districts invite sealed bids for the construction of schools, hospitals, and other public works to avoid corrupt selection processes. In avoiding what appear to be inflated price estimates, the selection committee may accept a low-bid that includes insufficient funds to adhere to building codes.

False Assumption \#8. Building codes are universally enforced in nations where they have been adopted.

In industrial and developing nations alike, earthquake resistant design codes are adopted at a national or regional level. Depending on the infrastructure of a country these measures may be weakly enforced at a local level, due to the absence of sufficient inspectors, or adequate training or guidance. Codes may not be mandated in small construction projects in some towns. In some developing nations, structures are built illegally on plots not owned by the builders, and without the assent of a building authority at all. Once constructed they are rarely demolished.

False Assumption \#9. Government building inspectors assure code adherence in engineered structures.

The job of a building inspector is to verify that each stage in construction has been achieved correctly and to approve or deny the builder proceeding to the next phase. Builders do not like to be kept waiting, especially if they have a payroll of workers on hold awaiting an inspection. A shortage of building inspectors means that these inspections may be undertaken lightly, or not at all. There are numerous opportunities for corrupt practices, especially where the ratio of the cost of building to an inspector's official income is large. In a recent case in Indonesia, officials were overwhelmed by the extent and type of damage and were unable to apply their judgment concerning the safety of surviving structures evenly and objectively throughout the damaged area.

False Assumption \#10. Licensed contractors adhere to building codes.

Hardened concrete can hide a multitude of sins, and few building inspectors have the authority or courage to ask for its removal in order to check what lies beneath its surface. In the absence of methods to test the integrity of a structure, contractors are often tempted to bury mistakes, or cover cheap materials beneath a veneer of concrete or paint.

False Assumption \#11. Homeowners build safer structures for themselves than when they employ contractors.

Very often a homeowner, or a group of families will team up to build one or more dwellings for themselves. The plan is usually to build a dwelling for their families with excess space for rental to others to recoup the construction costs. They buy the land, and stockpile the materials, purchasing minimum quantities of steel often of inferior quality and thickness. Construction occurs at weekends with no technical guidance. Their dwellings, through ignorance, may incorporate fatal flaws. Many examples of this practice were revealed after the Izmit earthquake of 1999.

False Assumption \#12. Urban planners with fixed budgets in earthquake prone regions prefer quality over quantity construction.

The pressure to satisfy a demand for maximum volume on a minimal budget may overwhelm decisions concerning the future safety of a community. An often quoted example attributed to A. S. Arya is the case where, faced with a cost decision to construct 200 new schools in India without earthquake resistance, or 180 schools with earthquake resistance, the local school authority approved construction of 200 schools without earthquake resistance.

False Assumption \#13. Government projects are always safer than privately-developed construction projects. 
The facts often indicate otherwise. In the 2005 earthquake in Kashmir more than 7,000 government-constructed schools were destroyed.

False Assumption \#14. Reconstruction of a city destroyed by an earthquake eliminates future seismic risk to its survivors.

A town that has been leveled by an earthquake is nowadays reconstructed rigorously to earthquake-resistant code, especially where international aid has been infused at a government level. The reconstructed town is now immune to damage from aftershocks. However, as time progresses, the new town may be considered by survivors to have none of the charm of their former city and gradually structures are added, or earthquake resistance is abandoned in favor of old habits. Adobe construction initially constructed as sheds for livestock, may eventually become homes for the children of survivors. Additional stories may be added to the original structures.

False Assumption \#15. A new generation of young earthquake engineers will fix the problems in their countries.

The importance of education is recognized by all developing nations, many of whom have established scholarships for their best young minds for advanced training at centres recognized for their competence in earthquake engineering throughout the world: in north America, Europe and Japan. A dedicated number of these young men and women return to their countries and do their best to apply their knowledge to the pressing and urgent problems of construction in their cities and villages. A subset, however, never return (the brain drain), or if they do, they become disillusioned by rampant corruption, and low salaries, and eventually join engineering companies elsewhere. When they do this they leave a vacuum that is filled by less well-trained engineers, some of whom may be unaware of earthquake resistant codes or design practices.

\section{Corruption}

Some of the above issues are attributable to ignorance, and others to complex societal pressures, but many of the problems I have identified can be classed as forms of corruption (6-10). The nature of corruption is that it is supposed to be invisible, and untraceable. Its effects are consequently difficult to quantify. Transparency International is a global organisation whose purpose is to identify corruption and through its exposure, to devise methods to eradicate or suppress its prevalance in society (http://www.transparency.org/). Their methods are to interview a cross-section of businessmen, travellers and residents to determine whether bribes are always, or nearly always, sometimes, rarely, or never, paid. Low scores (0) are awarded for "bribery always needed", high scores (10) for "never needed". A few thousand people are polled in each study. Their object is remove corrupt practices from the shadowy world under the table and to place them under a spotlight for all to see.

Transparency International reports that covert corruption in the $\$ 3,200$ billion/year construction industry exceeds any other sector of society. Bribery in the industry takes many forms: the corrupt award of construction projects, the corrupt issuance of approvals and permits, the corrupt inspection of all stages of construction, and the currupt concealment of shoddy work beneath concrete, plaster and cladding (Stansbury 2005).

A reality in many cities in the developing nations is that there is a disparity between available space and large populations. The construction industry is usually well funded, and in the developing nations, salaries are low in most of the offices where regulations must be implemented. In such a setting the conditions are ideal for nurturing corruption. The procedures of corruption once initiated, are designed to favor their persistence. 
In some cases corruption is quite overt. The absence of affordable housing leads to the growth of slums and unauthorized construction. Initially the slums start as tent cities using scavenged materials: plastic sheets, corrugated iron, adobe, hammered oil cans and scrap wood. As they become established, the squatters begin to feel that the land is theirs and in time undertake more elaborate additions: walls of brick or adobe, roofs, additional stories, tapping into water, electricity and gas through diabolically unsafe hook-ups. City officials designated to control illegal construction have a hard time characterizing such temporary structures in terms of any kind of code. Admonitions to desist are met with derision and indifference, since the hodge-podge of house materials is now "home", and there is nowhere for these impoverished city dwellers to go. Occasionally a bulldozer will scrape the settlement back to its former condition, or, very rarely, affordable housing will take its place, on the command of the city planners. The opportunity for bribes exist at all levels in a slum: payments to police to not clear away the settlement, payments to the electricity-man to not remove the cable to the power line, payments to water-man to look the other way when a water pipe taps the water main illegally.

New structures authorized by city planning authorites may be erected with overt application of bribes that speed construction but circumvent the safegaurds that ensure safe construction. Private developers may work with city officials to construct structures that are cheap, but which are known to be unsafe. Apartments are constructed that may differ in substantial ways from approved drawings. Fees are paid to prioritize water connections to lucrative developments, ahead of affordable housing communities. In some cities like Karachi, corruption has effectively replaced governance. It is always faster to pay a series of well-established but undocumented bribes, than to go through the authorized form-filling route to obtain city services. Housing, city road networks, and communal structures are founts of wealth for the unscrupulous. Officials and politicians may find themselves being pressured to exercise flexibility in the interpretation of building codes, for substantial sums. The resulting structures may contain numerous violations, to be discovered only when the structure collapses.

The above litany of societal evils (5-15) will disappear slowly, and in some cases not at all. Transparency International offers promising guidelines and ways to reduce the prevalence of bribery. Some forms of bribery are driven by poverty and greed. A subset of these problems, however, can be blamed on ignorance, and for this there is a fix-education.

\section{Education}

A scramble through the ruins of a city silenced by an earthquake can reveal any number of examples of faulty assembly. Many structural failures occur because builders did not know what they were doing. A common misconception revealed in post-seismic post-mortems is the function of horizontal stirrups wrapped around vertical re-bars in a concrete column. A wrapped stirrup is no mystery for an engineer who will explain that the stirrups are there to prevent the column from exploding in compression. For the homeowner house-builder, however, a stirrup appears to have the sole function of holding the vertical re-bar in place while the concrete is poured within its surrounding shuttering. If chicken wire will do it, why waste money cutting up an expensive piece of rebar? The builder, labourer, and contractor know that bits of metal are needed, but not why, and may be unaware that even thick stirrups need to be tied in a knot to prevent their unwrapping under extreme stress.

The stirrup-function problem falls into a class of knowledge that, like riding a bicycle, once mastered is never forgotten. There is no school for most of the world's laborers. They pick up their trade by default, and move on to new trades if opportunities arise. Common-sense 
does not fare well in a concrete-frame structure. A prelude to understanding the function of a stirrup is that the longitudinal vertical steel bar in the column is not there to carry a compressional load, so much as it is to prevent the column failing in tension. Again this is counterintuitive to most labourers. Few contractors will start a new apprentice with a short guide into the simplicity and elegance of concrete frame engineering. Usually the sole communication from the foreman is a series of instructions- "cut that bar into 18 inch lengths, bend them all like this one, and fix them on that half-finished pillar over there". There is no time for explanations of the laws of Physics.

The fix here is clear-house construction should be part of everyone's school education. An hour of how to mix cement, and the why-and-wherefore of structures would save many more lives than a sophisticated logic-tree investigation into the safety of a future civic structure. A student prepared with simple structural knowledge but destined for occupations other than the construction industry will benefit his/her future society by recognizing construction problems they may encounter throughout their lives. The lives they save may be their own. Some may become politicians or urban planners. All of them will live in a house.

\section{Responsibilities and monitoring}

The collapse of specific structures in earthquakes has occasioned retrospective enquiries into corrupt construction methods. Prior to a disaster, contractors and builders frequently pay lip-service to earthquake safety, since unlike cars or aircraft that are mass produced, the chances that a building will be damaged in the lifetime of the director of a construction company is perceived to be slender. Following a disaster it is possible for individuals responsible for construction to hide behind an infrastructure of architects, engineers, contractors, suppliers, inspectors and labourers. The builder's responsibility for the safety of a building is usually considered at an end once the key is in the hands of the new owner.

It is rather probable that the quality of buildings would improve substantially were builders to have their name inscribed on a building offering a money-back guarantee in the case of earthquake damage. It is equally certain that this would halt all new construction. Is there a middle-ground where the builder is placed in a position that alerts him to his responsibilities to future inhabitants?

Earthquake resistant codes are in effect designed to do this. By complying with codes a contractor is effectively absolved from responsibilities for failures. But the issue we face is the avoidance of codes through corrupt practices or inadequate inspection. Is there any way to monitor a dangerous structure once completed?

One possibility might be the implementation of black-box recorder on buildings, either during consruction or as a retrofit. The box need be no larger or more expensive than a personal music player (e.g. an iPOD). The heart of the box would be a strong motion sensor ostensibly to collect shaking intensities for future construction and microzonation, but with the implicit statement that the box is mandated to monitor structural integrity. The box would need minimal power, but an obvious location for it would be in the power distribution box common to all buildings. The meter-man could in fact collect building data from it regularly, or it could be hooked up to a computer network designed to monitor strong-motion accelerations.

The problem, of course, with this approach is that it adds an additional burden to the price of construction. The black-box recorder is equivalent in value to that critical handful of steel rods whose incorporation would have strengthened the building. Despite this shortcoming, 
the incorporation of a mandatory recorder on all new construction would result in a vast set of microzonation data for future engineers. It would add a trivial cost to most structures.

\section{A disparity in the cost of earthquakes}

Earthquake hazards and loss of life in an earthquake has been the central theme of this article, and yet the motivation for improved engineering is driven by the economic losses caused by earthquakes. I propose to largely ignore the numerous detailed studies of economic losses, and instead highlight a few key issues as they relate to fatalities. Earthquakes pose a difficulty for the insurance industry because they are infrequent and result in a huge variation in losses. The median loss is low but extreme events can expose the insurance companies to large losses (Scawthorn et al. 2003).

To compare earthquakes at different times, in the presence of inflation and changing demographics it is necessary to normalize both populations and values to a common number. Vranes and Pielke (2009) normalized the costs of twentieth century earthquakes to 2005-US dollars, and fatality counts to current populations (adjusted for city vulnerabilities). After these adjustments they find that the San Francisco earthquake and fire of 1906 was the most costly earthquake in US history weighing in at $\$ 284$ billion, followed by the Northridge earthquake of 1994 at $\$ 87$ billion, followed by the 1964 Alaska earthquake at $\$ 16$ billion, and a handful in the range 7-15\$ billion (Long Beach 1933, Loma Prieta 1989 and San Fernando 1971).

The total twentieth century US earthquake loss in 2005 dollars exceeded $\$ 448$ billion, with a cumulative adjusted death toll of 25,000 . A future $M=7.8$ earthquake in the Los Angeles region (the LA scenario event) were it to occur today was estimated recently to probably result in a death toll of 1,800 , accompanied by $\$ 200$ billion in damages. This is comparable to the cost of 1995 Kobe earthquake in Japan ( $\$ 173$ billion in reconstruction) that was accompanied by 5,000 fatalities.

These calculations divide the rich from the poor. Earthquakes in the developed nations are expensive but are accompanied by low fatality counts. In contrast, earthquakes in the developing nations cause immense loss of life and cost relatively little. The Kashmir 2005 earthquake, for example, resulted in more than 80,000 deaths and a $\$ 4$ billion reconstruction cost. The Indonesia/Andaman earthquake with its 290,000 death toll was associated with a $\$ 12$ billion recovery cost. Many of these costs were covered by international aid.

The trends depicted in Fig. 24 can be reduced to single numbers by taking the ratio of the fatality count to the cost in dollars. A vulnerability ratio can be defined as the number of fatalities $\times 10^{6}$ divided by the $\$$ damage cost (Vranes, personal communication, 2009). The vulnerability ratio for developed nations lies in the range $0.01 / \$-0.03 / \$$, while for the developing nations the ratio is three orders of magnitude worse, in the range $2 / \$-27 / \$$.

\section{Conclusions: the seismic future of cities}

The past 3,000 years of history reveals that as inhabitants of a seismically active planet we have been remarkably indifferent to the potential loss of life from earthquakes. Cities are not located to avoid earthquakes, are not moved when they are destroyed by them, and have until recently been reconstructed just as they were before destruction (Hough and Bilham 2006). Individuals are largely ignorant of the probability of an earthquake destroying their dwelling or workplace. Fewer individuals are aware of the weakness or strengths of their 
own dwellings, even in those rare cases where they have been directly involved in their construction.

At its simplest we can reduce our vision of the seismic future of cities to a handful of generalizations:

1. Most of the world's cities will never be damaged by an earthquake. A list of these "safest" cities, however, will almost certainly include some that will be damaged by a rare mid-plate earthquake (Fig. 16).

2. The global deathtoll from moderate earthquakes near human settlement is likely to average 8,000-10,000/year in the next several decades, punctuated by catastrophic individual earthquakes than may bring the decadal average to more than 50,000/year (Fig. 12; Table 2).

3. Future moderate earthquakes in the Industrial Nations are destined to be expensive but are likely to be accompanied by death-tolls of less than a few thousand. Large earthquakes near large cities may cost more than $\$ 200$ billion per event (Fig. 24).

4. Moderate earthquakes in the developing nations are likely to result in high death tolls, many exceeding 10,000 . The cost of rebuilding is likely to come in the form of disaster relief from the industrial nations.

5. A direct hit on a supercity once a century is statistically probable with a possible deathtoll exceeding 1 million. The odds of this happening in the industrial nations are low because buildings are in general resilient to shaking. Exceptions can be considered, e.g. a $\mathrm{Mw}=6$ earthquake in New York would damage many masonry structures constructed before seismic resistant codes were mandated (Tantala 2008). The odds of a mega-death-toll are higher in the developing nations because of the hazardous location of urban settlements, and the structural vulnerability of many of these cities. A Mw $\geq 7$ earthquake in Teheran could cause 1.4 million deaths.

6. In those countries in the developing nations where earthquake resistant construction has been implemented, the number of deaths from earthquakes in general shows little evidence of a decline (Figs.9, 10). Rising fatality rates have approximately paralleled population increase. One reason for this is the focus in many earthquake-prone regions on reconstructing recently damaged cities, rather than in reconstructing dwellings of those populations at risk in nearby cities where no recent earthquake has occurred.

7. In the developing nations, and in certain developed nations, corruption and ignorance currently circumvents the best efforts of the construction industry to build safe dwellings (Figs. 22, 23, 24). Both will need to be overcome if the projected increase in fatalities from earthquakes is to be arrested.

These simple conclusions follow from the observation that, in settlements in the developing word at least, a substantial fraction of dwellings are vulnerable to collapse when subject to quite modest shaking. The statistics shown in earlier chapters indicate that the death toll from earthquakes continues to rise, and with one exception, shows no tendency to decline. The exception is the recent slight decline in rate-of-increase in the cumulative number of fatalities from earthquakes that kill fewer than 30,000 people in the past decade. The decline is typical of fluctuations of rate observed in the past several decades, and is not considered significant.

It should be appalling to the people of the world that in 2009 , more than a 100 years after earthquake resistant construction began to be understood and implemented by engineers, that it is possible to write an article forecasting large numbers of future earthquake fatalities from the collapse of cities. Mallet and Milne would be disappointed, not only because they had recognized why buildings collapse in earthquakes, but also because since their times, most 


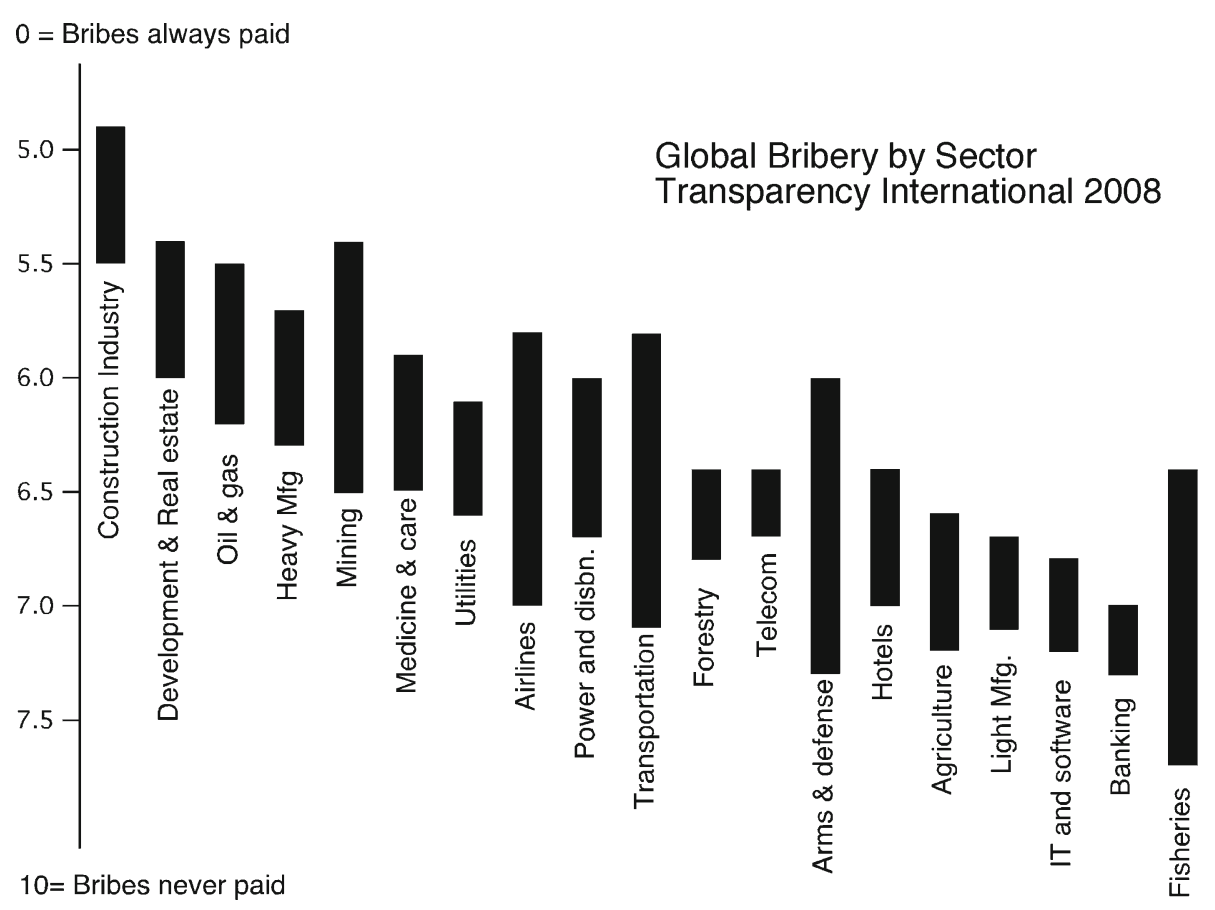

Fig. 22 Bribery reported in global polls by discipline from Transparency International 2008. The construction industry is the worse affected, with "development" and "real estate" a close second

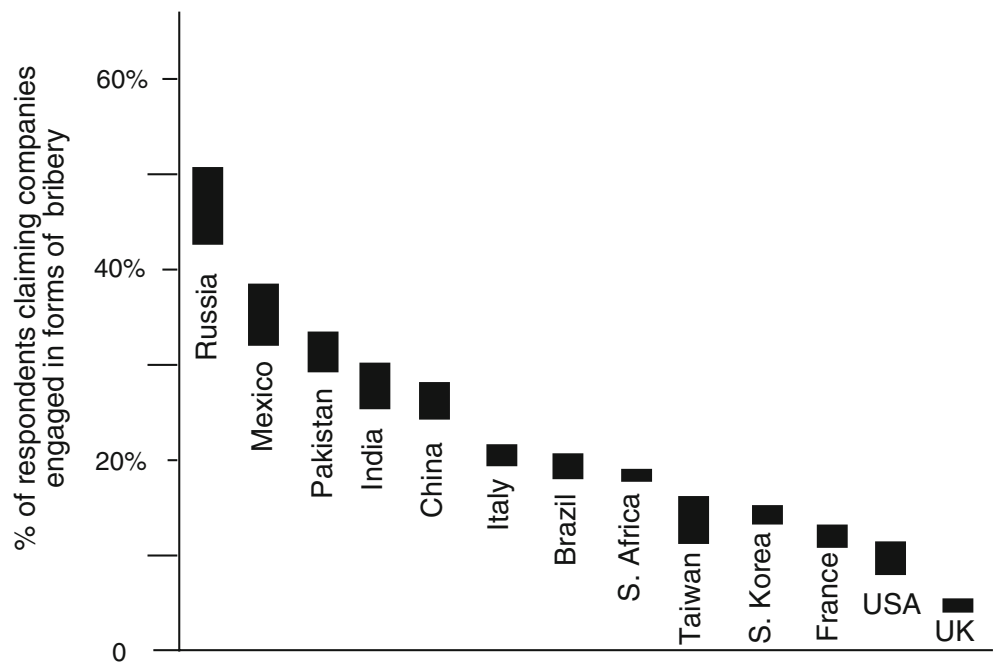

Fig. 23 Percentage of foreign respondents reporting companies engaged in some form of bribery for a subset of countries (from Transparency International, 2005 and 2008). The range for each country includes bribes paid to politicians and to officials to "help speed things up", and also includes the use of personal relationships in public contracting 


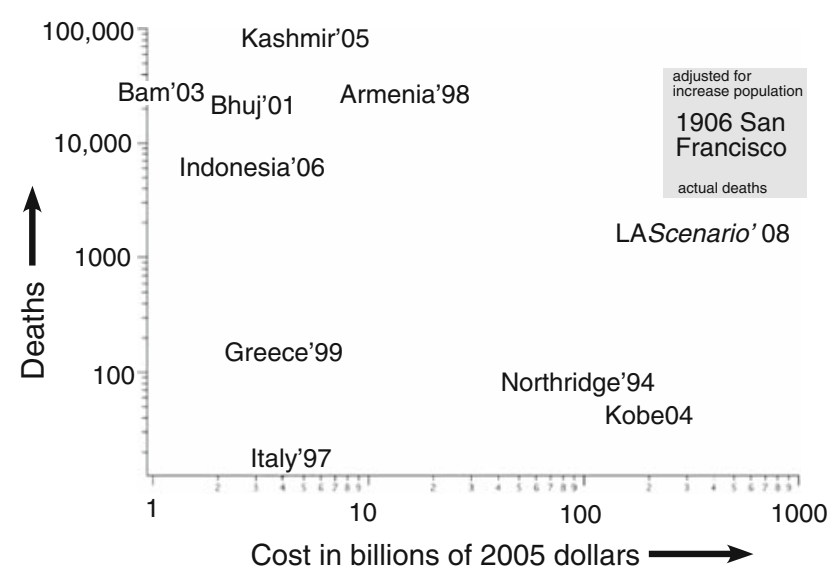

Fig. 24 Earthquake fatalities versus repair costs in 2005 US\$ (data from Vranes and Pielke 2009). The high pseudo-death-toll for the 1906 San Francisco earthquake plotted here is extrapolated for present-day population and vulnerability. The Scenario 2008 event is based on estimated \$ losses from a hypothetical M7.8 earthquake near Los Angeles (http://pubs.usgs.gov/of/2008/1150/). Tsunami-related deaths from the Indonesia 2004 earthquake are omitted

of the world's building stock has been replaced at least twice (assuming a 50 year life-span to most buildings). In addition, a four to sixfold increase in building stock has occurred. This constitutes a lost opportunity of massive proportions.

Underscoring this tragic lost opportunity, is the observation that we still live in a world where deaths are expected to accompany large earthquakes near cities. Within $30 \mathrm{~min}$ of a damaging earthquake we can quantify the number of fatalities and injuries anticipated in settlements surrounding the epicentre, before news of actual deaths are known on the ground. That this is possible admits that we have a problem in our cities that needs to be fixed. The time to have undertaken this fix was in the era of construction that started in about 1950. We have a further 30 years left in this global building boom, but it is unlikely that earthquake resistance will occur where the structures are going up most rapidly. The focus of earthquake resistance efforts should clearly be in the places where fatalities have been historically the worst-in the western Americas and in the Alpine/Himalayan/Indonesian collision belt. Given the present recession of world economies, the cost of the fix is likely to prevent the expenditure of funds where it matters most, at a time when it matters most. This suggests that urban populations will continue to be killed by earthquakes in the foreseeable future, and in greater numbers than in the documented past.

Acknowledgments I am grateful for discussions and suggestions from Nick Ambraseys, Paula Dunbar, Sarosh Lodi, Susan Hough, Stacey Martin, Brian Tucker, Dave Wald, and Max Wyss. GPS and strain data were made available by UNAVCO, Inc. I thank Nick Ambraseys, Zygmunt Lubko, Clark Fenton and Roger Musson for reviewing and suggesting improvements to the text. The research was funded at various times in the past few decades by NEHRP, the National Science Foundation and by the John Simon Guggenheim Foundation.

Open Access This article is distributed under the terms of the Creative Commons Attribution Noncommercial License which permits any noncommercial use, distribution, and reproduction in any medium, provided the original author(s) and source are credited. 


\section{References}

Albini P (2004) A survey of the past earthquakes in the Eastern Adriatic (14th to early 19th century). Ann Geophy 47:675-703

Allen T, Marano KD, Earle PS, Wald DJ (2009) PAGER-CAT: a composite earthquake catalogue for calibrating global fatality models. Seismol Res Lett 80: 57-62. doi:10.1785/gssrl.80.1.57

Amante C, Eakins BW (2008) ETOPO1 1 arc-minute global relief model: procedures, data sources and analysis. National Geophysical Data Centre, NESDIS, NOAA, US Department of Commerce, Boulder

Ambraseys N (1962) A note on the chronology of Willis of earthquakes in Palestine and Syria. Bull Seism Soc Am 52:77-89

Ambraseys NN (2004) Three little known early earthquakes in India. Curr Sci 86(4):506-508

Ambraseys NN (2009) Earthquakes in the eastern Mediterranean and the Middle East: a multidisciplinary study of 2,000 years of seismicity, Cambridge University Press (ISBN 9780521872928)

Ambraseys NN, Jackson JA, Melville CP (2002) Historical seismicity and tectonics: the case of the Eastern Mediterranean and the Middle East. Int Handb Earthq Eng Seismol 81:747-763

Ambraseys NN, Jackson D (2003) A note on early earthquakes in northern India and southern Tibet. Curr Sci 84:570-582

Ambraseys N, Melville C (1982) A history of Persian earthquakes. Cambridge University Press, Cambridge

Anthon C (1850) A system of ancient and medieval geography. Harper and Brothers, NY, p 769

Ball JD (1904) "Things Chinese" or notes connected with China, 4th edn. Scribner, NY 816

Beavan J, Haines J (2001) Contemporary horizontal velocity and strain rate fields of the Pacific-Australian plate boundary zone through New Zealand. J Geophys Res 106:741-770

Belletatti D, Camassi R, Molin D (2007) Fake quakes in Italy through parametric catalogues and seismological compilations: case histories and typologies. Terra Nova 5:488-495

Bibliotheca Indica (1874) Asiatic Soc India, Thomas, Baptist Mission Press, Calcutta, 66, p 74

Bilham R (1988) Earthquakes and urban growth. Nature 336:625-626

Bilham R (1994) The 1737 Calcutta earthquake and cyclone evaluated. Bull Seism Soc Am 84(5): $1650-1657$

Bilham R (1995) Global fatalities from earthquakes in the past 2,000years: prognosis for the next 30. In: Rundle J, Klein F, Turcotte D (eds) Reduction and predictability of natural disasters. Santa Fe institute studies in the sciences of complexity, vol XXV. Addison Wesley, Reading, MA, pp 19-31

Bilham R, Bendick R, Wallace K (2003) Flexure of the Indian plate and intraplate earthquakes. Proc Indian Acad Sci (Earth Planet Sci) 112(3):1-14

Bilham R (2004) Global urban earthquakes: a safer world or worse to come? . Seism Res Lett 75(6):706-712

Bilham R (2008) Tsunamigenic middle earth. Nat Geosci 1:211-212

Bilham R, Gaur VK, Molnar P (2001) Himalayan seismic hazard. Science 293:1442-1444

Bilham R, Wallace K (2005) Future Mw > 8 earthquakes in the Himalaya: implications from the 26 Dec 2004 $\mathrm{Mw}=9.0$ earthquake on India's eastern plate margin. Geol Surv India Spl Pub 85:1-14

Bilham R, Szeliga W (2008) Interaction between the Himalaya and the flexed Indian plate-spatial fluctuations in seismic hazard in India in the past millennium? 2008 Seismic enginering conference commemorating the 1908 Messina and Reggio Calabria earthquake. Santini A, Moraci N (eds) American Institute of Physics Conference Proceeding 1020(1), pp 224-231, (978-0-7354-0542-4/08)

Bilham R, Lodi S, Hough S, Bukhary S, Khan AM, Rafeeqi SFA (2007) Seismic hazard in Karachi, Pakistan: uncertain past, uncertain future. Seism Res Lett 78(6):601-631

Biraben J-N (1980) An essay concerning mankind's evolution, population, selected papers, December, Table 2

Brunn DS, Williams J, Zeigler DJ (2003) Cities of the world: world regional urban development, Rowman and Littlefield, 548 pp. ISBN 084769898X, 9780847698981

Byrne DE, Sykes LR, Davis DM (1992) Great thrust earthquakes and aseismic slip along the plate boundary of the Makran subduction zone. J Geophys Res 97:449-478

Chandler T (1998) Four thousand years of urban growth: an historical census. St. David's University Press, Lewiston, New York, 1987, $656 \mathrm{p}$

Chandler T, Fox G (1974) 3,000 years of urban growth. Academic press, New York 431

Clark D (2003) Urban world/global city. Routledge, 235 pp, ISBN 0415320976, 9780415320979

Cornell CA (1968) Engineering seismic risk analysis. Bull Seism Soc Am 58:1583-1606

Correia-Alphonso J (1969) Jesuit letters and Indian History 1542-1773. Oxford University Press, Oxford 211

Cunningham A (1871) The ancient geography of India. Trubner and Co., London, 770 pp

DeMets C, Gordon RG, Royer J-Y (2005) Motion between the Indian, Capricorn and Somalian plates since 20 Ma: implications for the timing and magnitude of distributed lithospheric deformation in the equatorial Indian ocean. Geophys J Int 161:445-468 
Dilley M (2005) Natural disaster hotspots: a global risk analysis. Published by World Bank Publications, 132 pp, ISBN 0821359304, 9780821359303

Drake NF (1912) Destructive earthquakes in China. Bull Seismol Soc Am 2(1):40-91

Dunbar PK, Lockridge PA, Whiteside LA (1992) Catalogue of significant earthquakes (2150 BC-1991 AD), Report SE-49, National Oceanic and Atmospheric Administration

Duncan DE (1998) Calendar. Avon Books, NY 266

Durand JD (1974) Historical estimates of world population: an evaluation. University of Pennsylvania, Population Centre. Analytical and Technical Reports, Number 10, Table 2

Eberhart-Phillips JE, Saunders TM, Robinson AL, Hatch DL, Parrish RG (1994) Profile of mortality from the 1989 Loma Prieta earthquake using coroner and medical examiner reports. Disasters 18(2):160-170

Elliot HM (1857) In: Dowson (ed) The history of India as told by its own historians: the Muhammadan period, vol 8, 3rd edn. Trubner and Co., London, pp 1867-1878

England P, Molnar P (1990) Right-lateral shear and rotation as the explanation for strike-slip faulting in eastern Tibet. Nature 344: 140-142. doi:10.1038/344140a0

Gabaix X, Ioannides YM (2003) The evolution of city size distributions, Discussion Papers Series, Department of Economics, Tufts University 0310, Department of Economics, Tufts University, pp 1-51

Ganse RA, Nelson JB (1982) Catalogue of significant earthquakes 2000 BC to 1979, including quantitative casualties and damage?. Bull Seismol Soc Am 72(3):873-877

Ghafur MA (1966) Fourteen Kufic inscriptions of Banbhore, the site of Daybul. Pak Archeol 3:65-91

Gouin P (1979) Earthquake history of ethiopia and the horn of Africa. International Development Research Centre, Ottawa, IDRC- $118 \mathrm{e}$, p 259

Gripp AE, Gordon RG (1990) Current plate velocities relative to the hotspots incorporating the NUVEL-1 global plate motion model. J Geophys Res 17(8):1109-1112

Gripp AE, Gordon RG (2002) Young tracks of hotspots and current plate velocities. Geophys J Int 150: 321361. doi:10.1046/j.1365-246X.2002.01627.x

Guidoboni E, Ebel JE (2009) Earthquakes and Tsunamis in the past: a guide to techniques in historical seismology. Cambridge University Press, pp 462-464

Guidoboni E, Comastri A, Traina G (1994) Catalogue of ancient eathquakes in the Mediterraneum area up to the 10th century, vol 2. ING-SGA, Bologna

Haines AJ, Holt WE (1993) A procedure for obtaining the complete horizontal motions within zones of distributed deformation from the inversion of strain rate data. J Geophys Res 98:12057-12082

Haines AJ, Jackson JA, Holt WE, Agnew DC (1998) Representing distributed deformation by continuous velocity fields, Sci Rept 98/5. Inst of Geol and Nucl Sci, Wellington, New Zealand

Haub C (1995) How many people have ever lived on earth? Popul Today, 23(2):5-10

Hirota S (1908) A catalogue of Chinese earthquakes. Report of the seventy-eighth meeting of the British Association for the Advancement of Science, Dublin, 1907, pp 82-112

Hodīvālā SH (1939) Studies in Indo-Muslim history: a critical commentary on Elliot and Dowson's history of India as told by its own historians. 1:712. Kokil and Co

Hoff KEA (1840) Chronik der Erdbeben und Vulcan Ausbrüche, IV. Gotha, p 470

Hough SE, Martin S (2002) Magnitude estimates of two large aftershocks of the 16 December, 1811 New Madrid earthquake. Bull Seismol Soc Am 92:3259-3268

Hough S, Bilham R (2006) After the earthquakes. Oxford, p 321

Hurd RM (1903) Principles of city land values. Real Estate Record Association. The Record and Guide, 4th edn. (1924), $159 \mathrm{pp}$

Jackson J (2006) Fatal attraction: living with earthquakes, the growth of villages into megacities, and earthquake vulnerability in the modern world. Phil Trans R Soc A 364: 1911-1925. doi:10.1098/rsta.2006. 1805

Jackson JA, Blenkinsop T (1993) The Malawi earthquake of 10 March 1989: deep faulting within the East African rift system. Tectonics 12:1131-1139

Jain SK, Murty CVR, Chandiak N, Seeber L, Seeber NK, Jain NK (1994) The September 29, 1993, M6.4 Killari. Maharasthtra earthquake in Central India, EERI Newsletter 28(1)

Johnston AC, Schweig ES (1996) The enigma of the New Madrid earthquakes of 1811-1812. Ann Rev Earth Planet Sci 24:339-384

Kanamori H, Hauksson E, Heaton TR (1997) Realtime seismology and hazard mitigation. Nature 390: 461-462

Khan FA (1964) Excavations at Bhanbore. Pak Archaeol 1:49-55

Klein-Goldweijk CGM, Battjes JJ (1997) A hundred year data base for integrated environmental assessments. (HYDE, version 1.1) Report 42254002. Nartional Institute of Public Health and environment (RIVM) Bilthoven, The Netherlands 
Kovach RL, Grijalva K, Nur A (2008) Earthquakes and civilizations of the indus valley: a challenge for archaeoseismology. Seismol Res Lett 79(2):290

Kreemer C, Haines J, Holt WE, Blewitt G, Lavallée D (2000) On the determination of a global strain rate model. Earth Planets Space 52:765-770

Kreemer C, Holt WE, Haines AJ (2003) An integrated global model of present-day plate motions and plate boundary deformation. Geophys J Int 154:8-34

Krinitzsky EL (1995) Problems with logic trees in earthquake hazard evaluation. Eng Geol 39:1-3

Kumar S, Wesnousky SG, Rockwell TK, Briggs RW, Thakur VC, Jayangondaperumal R (2006) Palæoseismic evidence of great surface rupture earthquakes along the Indian Himalaya. J Geophys Res 111:B03304. doi:10.1029/2004JB003309

Latter JH (1969) Natural disasters. Adv Sci 25:362-380

Lavé J, Yule D, Sapkota S, Basenta K, Madden C, Attal M, Pandey R (2005) Evidence for a great Medieval earthquake ( AD 1100) in Central Himalaya, Nepal. Science 307:1302-1305

Lee WHK, Wu FT, Jacobsen C (1976) A catalogue of historical earthquakes in China compiled from recent Chinese publications. Bull Seismol Soc Am 66(6):2003-2016

Mallet R (1851) Report of the twentieth meeting of the British association for the advancement of science, Edinburgh, 1850. First Report on the Facts of Earthquake Phenomena, pp 1-88

Mallet R (1852) Report of the twenty-first meeting of the British association for the advancement of science, Ipswich, 1851. Second Report on the Facts of Earthquake Phenomena, pp 272-320

Mallet R (1853) Report of the twenty-second meeting of the British association for the advancement of science, Belfast, 1852. Third Report on the Facts of Earthquake Phenomena, pp 1-176

Mallet R (1854) Report of the Twenty-third meeting of the British association for the advancement of science, Hull, 1853. Third Report on the Facts of Earthquake Phenomena. Catalogue of Recorded Earthquakes from $1606 \mathrm{BC}$ to AD 1850, continued, pp 117-212

Mallet R (1855) Report of the twenty-fourth meeting of the British association for the advancement of science, Liverpool, 1854. Catalogue of Recorded Earthquakes from 1606 BC to AD 1850 (continued from Report for 1853), pp 2-326

Mallet R (1862) Great Neapolitian earthquake of 1857. The first principles of observational seismology 1. Chapman and Hall, London 67-68

Martin S, Szeliga W (2009) Re-evaluated macroseismic data for earthquakes in the Indian Subcontinent. Bull Seismol Soc Am (in press)

Marza VI (2004) On the death toll of the 1999 Izmit (Turkey) major earthquake. ESC General Assembly Papers, European Seismological Commission, Potsdam

May PJ (2001) Societal perspectives about earthquake performance: the fallacy of "Acceptable Risk". Earthq Spectra 17:725. doi:10.1193/1.14239

McEvedy C, Jones R (1978) Atlas of world population history. Facts on File, New York 342-351

McGuire B (2004) World Atlas of natural hazards. Arnold, 120 pp. ISBN 0340764058, 9780340764053

McKenzie D (1978) Active tectonics of the Alpine-Himalayan belt: the Aegean Sea and surrounding regions. Geophys J Int 55(1):217-254

Mellaart J (1967) Çatal Hüyük: a neolithic town in Anatolia. Thames and Hudson, London

Milne J (1891) Earthquakes and other earth movements. Appleton, NY 363

Milne J (1912) A catalogue of destructive earthquakes, AD 7-1899. British Association for the Advancement of Science. Portsmouth 1911, p 92

Murty TS, Rafiq M (1991) A tentative list of tsunamis in the marjinal seas of the north Indian Ocean. Nat Hazards 4:81-83

Musson R (2004) Historical earthquakes of the British Isles. In: Lee WK, Kanamori H, Jennings PC, Kisslinger $\mathrm{C}$ (eds) International handbook of earthquake engineering and seismology. Academic Press, Amsterdam pp 691-717

Nateghi AF (2001) Earthquake Scenario for the mega-city of Teheran. Disaster Prevention and Management 10(2):95-100. MCB Univeristy Press ISSN-0965-3562

Nichols JM, Beavers JE (2003) Development and calibration of an easrthquake fatality function. Earthq Spectra 19(3):605-633

Nishenko SK, Barton CC (1996) Scaling laws for natural disasters, Reduction and predictability of Natural Disaters eds Rundle, Turcotte and Klein, Sante Fe Stucies of Complexity, 25 Addison Wesley

Oldham RD (1899) Report on the great earthquake of 12th June 1897 (incl. the reports by P. Bose, G. Grimes, H. Hayden, T. LaTouche and E. Vredenburg), Mem Geol Surv India, 29, pp 1379, Calcutta

Oldham T (1883) A Catalogue of Indian earthquakes. In: Oldham RD (ed) Mem Geol Surv India, 19:163-215, Geol Surv India, Calcutta

Peden MM (2004) World report on road traffic injury prevention: on road traffic injury prevention, $217 \mathrm{pp}$. World Health Organization, World Bank, ISBN 9241562609, 9789241562607, p 217 
Perrey A (1844-1853) Liste des tremblements de Terre, Partie des Sciences Physiques et Chemiques. Comptes Rendus des Travaux Academie des Sciences

Porter KA (2003) Seismic vulnerability 21(1-41). In: Chen W-F, Scawthorn C (eds) Earthquake engineering handbook, CRC Press, Boca Raton

Pumain D (1982) La dynamique des villes. Economica, Paris, p 231. ISBN 10: 2717804706

Rikitake T (1976) Earthquake prediction. Elsevier, pp 357

Sarkar J (1947) Maasir-i-Alamgiri-an english translation of Saqi Must'ad Khan's history of the Emperor Aurangzib. Suhail Academy Reprint 1981, Lahore, p 350

Scawthorn C, Kunreuther H, Roth R (2003) Insurance and financial risk transfer, 32(1-34). In: Chen W-F, Scawthorn C (eds) Earthquake engineering handbook. CRC Press, Boca Raton, FL

Scholz CH (2002) The mechanics of earthquakes and faulting, 2nd edn., Cambridge, p 219

Schurhammer G (1962) Die zeitgenössischen Quellen zur Geschichte Portugiesisch-Asians und Seiner Nachtbarländer zur Zeit des Hl. Franz Xaver (1538-1552) (trans: Costelloe MJ, Francis Xavier SJ). His Life and Times, Jesuit Historical Institute, Rome (1973)

Seeber L, Ekstrom G, Jain SK, Murty CVR, Chandak N, Armbruster JG (1996) The 1993 Killari earthquake in central India: a new fault in Mesozoic basalt flows?. J Geophys Res 101:8543-8560

Seligson HA, Shoaf KI (2003) Human impacts of earthquakes, 28(1-25). In: Chen W-F, Scawthorn C (eds) Earthquake engineering handbook. CRC Press, Boca Raton

Shaw B, Ambraseys NN, England PC, Floyd MA, Gorman DJ, Higham TFG, Jackson JA, Nocquet J-M, Pain CC, Piggott MD (2008) Eastern Mediterranean tectonics and tsunami hazard inferred from the AD 365 earthquake. Nat Geosci 1:268-276

Stucchi M, Galadini F, Rovida A, Moroni A, Albini P, Mirto C, Migliavacca P (2008) Investigation of pre-1700 earthquakes between the Adda and the Middle Adige river basins (Southern Alps). In: Fréchet J et al (eds) Historical seismology. Springer Science+Business Media B.V. 2008, pp 93-129

Stansbury N (2005) Preventing corruption on construction projects: risk assessment and proposed actions for consrtruction and engineering companies and consulting engineering firms, Transparency International [http://www.transparency.org/global_priorities/public_contracting/projects_public_contracting/ preventing_corruption_in_construction]

Tantala MW, Nordenson GJP, Deodatis G, Jacob K (2008) Earthquake loss estimation for the New York City metropolitan region. Soil Dyn Earthq Eng 28:812-835

Taylor PJ (2003) World city network: a global urban analysis Routledge. ISBN 041530248X, 9780415302487, $256 \mathrm{pp}$

Thenhaus PC, Campbell KW (2003) Seismic hazard analysis 8(1-43). In: Chen W-F, Scawthorn C (eds) Earthquake engineering handbook. CRC Press, Boca Raton

Thomlinson R (1975) Demographic problems, controversy over population control, 2nd edn. Table 1

Tobriner S (2006) Bracing for disaster: earthquake-resistant architecture and engineering in San Francisco, 1838-1933

Tucker BE, Erdik M, Hwang CN (1994) Issues in urban earthquake risk. In: Proceedings of the NATO advanced research workshop on 'an evaluation of guidelines for developing earthquake damage scenarios for urban areas,' Istanbul, Turkey, October 8-11, 1993. Published by Springer, 1994, ISBN 0792329147, 9780792329145,329 pp

US Census Bureau (2008) Total midyear population for the world: 1950-2050. Data updated 15 Dec 2008

United Nations (1999) The world at six billion, Table 1, world population from year 0 to stabilization, p 5. United Nations Population Division. http://www.un.org/esa/population/unpop.htm

United Nations (2009) World population prospects. The 2008 revision. http://esa.un.org/unpp/

Utsu T (2002) A list of deadly earthquakes in the world: 1500-2000. In: Lee WK, Kanamori H, Jennings PC, Kisslinger C (eds) International handbook of earthquake engineering and seismology. Academic Press, Amsterdam and Boston pp 691-717

Vranes K, Pielke R (2009) Normalized earthquake damages and fatalities in the United States: 1900-2005. Nat Hazards Review (in press)

Wald DJ, Quitoriano V, Heaton TH, Kanamori H, Scrivner CW, Worden BC (1999) TriNet "Shakemaps"; rapid generation of peak ground motion and intensity maps for earthquakes in southern California. Earthq Spectra 15:537-556

Waugh WL (1998) Living with hazards, planning for disasters, Sharpe, $240 \mathrm{pp}$

Wells DL, Coppersmith KJ (1994) New empirical relationships among magnitude, rupture length, rupture width, rupture area, and surface displacement. Bull Seismol Soc Am 84(4):974-1002

Wenzel F, Bendimerad F, Sinha R (2007) Megacities-Megarisks. Nat Hazards 42: 481-491. doi:10.1007/ s11069-006-9073-2

Wesnousky SG, Kumar S, Mohindra R, Thakur VC (1999) Uplift and convergence along the Himalayan frontal thrust of India. Tectonics 18:967-976 
Willis B (1928) Earthquakes in the Holy Land. Bull Seismol Soc Am 18:72-103

Wyss M (2004) Real-time prediction of earthquake casualties. In: Malzahn D, Plapp T (eds) Disasters and society—-from hazard assessment to risk reduction. Logos, Karlsruhe pp 165-173

Wyss M (2005) Human losses expected in Himalayan earthquakes. Nat Hazards 34(3):305-314

Yong C, Tsoi KL, Feibi C, Zhenhuan G, Qijia Z, Zhangli C (1988) The great Tangshan earthquake of 1976: an anatomy of disaster. Pergamon Press, p 162, ISBN-13: 978-0080348759 